\title{
Vertical control in the Class III compensatory treatment
}

\author{
Márcio Costa Sobral ${ }^{1}$, Fernando A. L. Habib², Ana Carla de Souza Nascimento ${ }^{3}$
}

Introduction: Compensatory orthodontic treatment, or simply orthodontic camouflage, consists in an important alternative to orthognathic surgery in the resolution of skeletal discrepancies in adult patients. It is important to point that, to be successfully performed, diagnosis must be detailed, to evaluate, specifically, dental and facial features, as well as the limitations imposed by the magnitude of the discrepancy. The main complaint, patient's treatment expectation, periodontal limits, facial pattern and vertical control are some of the items to be explored in the determination of the viability of a compensatory treatment. Hyperdivergent patients who carry a Class III skeletal discrepancy, associated with a vertical facial pattern, with the presence or tendency to anterior open bite, deserve special attention. In these cases, an efficient strategy of vertical control must be planned and executed. Objective: The present article aims at illustrating the evolution of efficient alternatives of vertical control in hiperdivergent patients, from the use, in the recent past, of extra-oral appliances on the lower dental arch (J-hook), until nowadays, with the advent of skeletal anchorage. But for patients with a more balanced facial pattern, the conventional mechanics with Class III intermaxillary elastics, associated to an accentuated curve of Spee in the upper arch and a reverse Curve of Spee in the lower arch, and vertical elastics in the anterior region, continues to be an excellent alternative, if there is extreme collaboration in using the elastics.

Keywords: Orthodontics. Class III malocclusion. Camouflage.

Introdução: o tratamento ortodôntico compensatório, ou simplesmente camuflagem ortodôntica, consiste em uma importante alternativa à cirurgia ortognática na resolução de discrepâncias esqueléticas em pacientes adultos. Torna-se importante salientar que, para ser instituído de maneira bem-sucedida, deve-se realizar detalhado diagnóstico, avaliando de maneira específica as características dentárias e faciais, assim como as limitações impostas pela magnitude da discrepância. A queixa principal, as expectativas do paciente frente ao tratamento, os limites periodontais, padrão facial e controle vertical são alguns dos itens a serem explorados na determinação da viabilidade de um eventual tratamento compensatório. Os pacientes portadores de discrepância esquelética de Classe III associada a padrão facial vertical, hiperdivergente, com a presença ou tendência à mordida aberta anterior, merecem uma atenção especial. Nesses casos, uma eficiente estratégia de controle vertical deve ser planejada e instituída. Objetivo: o presente artigo tem como objetivo ilustrar a evolução de alternativas eficientes para controle vertical em pacientes hiperdivergentes - desde a utilização, em um passado recente, de dispositivos extrabucais na arcada inferior (J-hook), indo até os dias atuais, com o advento da ancoragem esquelética. Já para pacientes com um padrão facial mais equilibrado, a mecânica convencional com elásticos intermaxilares na direção de Classe III, associada à curva de Spee acentuada na arcada superior, reversa na inferior e elásticos verticais na região anterior, continua sendo uma excelente alternativa, desde que haja extrema colaboração na utilização dos elásticos.

Palavras-chave: Ortodontia. Má oclusão de Classe III. Camuflagem.

${ }^{1} \mathrm{MSc}$ in Orthodontics, Federal University of Rio de Janeiro (UFRJ). Professor, Specialization Program of Orthodontics, Federal University of Bahia (UFBA). Diplomate by the Brazilian Board of Orthodontics and Facial Orthopedics (BBO). ${ }^{2} \mathrm{PhD}$ in Dentistry, Federal University of Bahia (UFBA). Specialist in

Orthodontics, Federal University of Rio de Janeiro (UFRJ). Associate Professor of Orthodontics, Federal University of Bahia (UFBA).

${ }^{3}$ Specialist in Orthodontics, Federal University of Bahia (UFBA).

» Patients displayed in this article previously approved the use of their facial and intraoral photographs.
How to cite this article: Sobral MC, Habib FAL, Nascimento ACS. Vertical control in the Class III compensatory treatment. Dental Press J Orthod. 2013 Mar-Apr;18(2):141-59.

Submitted: January 24, 2013 - Revised and accepted: March 27, 2013

» The author reports no commercial, proprietary or financial interest in the products or companies described in this article.

Contact address: Márcio Costa Sobral

Av. Anita Garibaldi, 1815, sala 315-B, C.M.E. - Ondina, Brazil CEP: 41.170-130, Salvador / BA - E-mail: marciosobral@gmail.com 


\section{INTRODUCTION}

The universe of eventual patients liable to orthodontic treatment can be divided into two large groups: With or without skeletal discrepancies. The latter, in turn, is subdivided into the presence or absence of facial growth potential, a relevant fact for the elaboration of the treatment plan, as well as to the prognosis estimate.

The interceptive treatment of important skeletal discrepancies on young patients with growth potential, together with corrective orthodontic procedures, in a subsequent step, can, in theory, redirect facial growth. Such an intervention can minimize and even correct those discrepancies, promoting good occlusion, balance between the jaws, and adequate facial esthetics.

On the other hand, for those who have already finished the outbreak of puberal growth, there are only two alternatives: Compensatory orthodontic treatment, also known as orthodontic camouflage, or orthodontic treatment associated to orthognathic surgery. The decision on what to be performed must be made together with the patient, taking into account the following aspects: Main complaint and yearnings about the treatment results, severity degree of maxillary-mandibular discrepancy, periodontal limits for orthodontic movement, clinical condition of present teeth and the impossibility of growth modification.

\section{ORTHODONTIC CAMOUFLAGE}

Orthodontic camouflage consists on the displacement of teeth in relation to the supporting bone, to compensate the discrepancy between the jaws. It can be accomplished by dental inclination. Depending on the desired level of compensation and the magnitude of orthodontic movement, some times extractions are needed.

As suggested by Proffit et $\mathrm{al}^{1}{ }^{1}$ there is a limit for incisor orthodontic movement, that is, in some cases, orthodontic treatment has to be associated with the movement of the basal bones by facial orthopedics or orthognathic surgery. However, dental movement can camouflage a broad variety of skeletal discrepancies, without deleterious effects on the periodontal structures. Nevertheless, correct diagnosis and a realistic treatment plan are necessary to avoid undesirable sequelae. ${ }^{5}$

Orthodontic camouflage is well fit for patients that carry small skeletal Class III, with no growth po- tential, with a relative fine facial balance and without severe crowding. Almost always, the compensatory orthodontic treatment is followed by the patient fear of facing surgical procedure, and by his relative satisfaction with his facial aspect, generating a small demand for great changes on this feature.

In relation to Class III, when the skeletal problem is small, the facial aspect is improved after camouflage; however, in moderate and severe cases, orthodontic treatment produces considerable worsening on facial esthetics, because the slightest retraction of lower incisors increases the chin prominence. ${ }^{1}$

When asymmetry is added to the skeletal discrepancy, it is imperative to pay attention in the patients' expectations concerning treatment, because orthodontic camouflage is not going to correct it. Yet, facial asymmetry may not cause great impact on esthetics or, even if it is noticed, the patient may reject surgical treatment.

\section{CLASS III CAMOUFLAGE - CLINICAL AND MECHANICAL ASPECTS}

Early intervention on skeletal Class III discrepancies, in the mixed dentition and even in the deciduous dentition, is more and more attracting orthodontist's attention. However, the skeletal Class III pattern worsens with age, that is, the deformity, apparently corrected during childhood, presents relapse during adolescence. This brings great difficulties to treatment success of the problem..$^{2,7}$ Nevertheless, patients with light or moderate skeletal Class III malocclusion and with acceptable facial esthetics can benefit from a compensatory orthodontic treatment. ${ }^{4}$

The strategy to camouflage a Class III malocclusion usually involves buccal inclination of upper incisors and retroinclination of lower incisors to improve dental occlusion, but it does not correct the skeletal problem or modify facial profile in a meaningful way. ${ }^{5,6}$

It is important to notice the cases in which the facial type of the patient is characterized as vertical and/ or with a hiperdivergent tendency, or with anterior open bite. In those cases it is necessary to associate vertical control strategies during tooth movement, with the goal of avoiding undesirable opening of the mandibular plane, which would meaningfully worsen the vertical relation on the anterior region, hampering or even stopping the achievement of a satisfactory 
occlusion at the end of the treatment. One of the effective ways to accomplish vertical control remounts to the mechanical principles of Tweed-Merrifield technique, that nowadays, associated with skeletal anchorage devices, are extremely predictable and easily used by patients. ${ }^{12}$

Orthodontic camouflage treatment must be indicated for young patients, only if, before starting treatment, cephalometry shows that residual growth is not going to aggravate the deformity after treatment. ${ }^{6} \mathrm{Be}-$ sides, most of the patients that have a serious Class III skeletal deformity are liable to orthognathic surgery as the only option to obtain both normal occlusion and a pleasant profile, concerning esthetics. ${ }^{2}$

The goal of the present article is to illustrate the evolution of efficient strategies of vertical control in hyperdivergent patients, since the use, in the recent past, of extraoral devices on the lower arch (J-hook), until nowadays, with the advent of skeletal anchorage. But, for patients with a more balanced facial pattern, the conventional mechanics with intermaxillary elastics in Class III direction associated to an accentuated curve of Spee on the upper arch, and a reverse Curve of Spee in the lower arch, and vertical elastics in the anterior region, continues to be an excellent alternative, if there is extreme collaboration on the use of the prescribed mechanics.

\section{PATIENTS WITH A BALANCED FACIAL PATTERN}

\section{Case 1 - Class III with anterior open bite and posterior bilateral crossbite, treated with extractions (\#38, \#48)}

" Vertical control: Accentuated curve of Spee on the upper arch, reverse on lower arch and vertical elastics on anterior region.

\section{History and etiology}

The patient, 27 years old, presented for the initial exam in a good general state of health. His main complaint reported functional problems related to mastication. Facial esthetics did not seem to be a concern (Fig 1). With more detailed examination of the occlusion, a disharmony between the maxilla and the mandible, in the anteroposterior direction was noticed. There was no reference to Class III in his family medical history.

\section{Diagnosis}

Regarding facial features, he presented a mesocephalic facial type, with a straight profile, proportional and harmonious facial third, lip competence at rest, and absence of evident asymmetries. The smile was unbalanced, with exposure of lower incisors (Fig 1).

In the dental aspect, he presented an Angle Class III malocclusion, with anterior open bite $(2 \mathrm{~mm})$, posterior bilateral crossbite, edge to edge relationship of incisors. Also, a $2 \mathrm{~mm}$ anteroinferior crowding was noticed, with rotations of central incisors and canines with mesial angulation; coincident midlines (Fig 1); good oral hygiene and healthy periodontium.

The panoramic radiograph analysis did not show any significant alteration that could contraindicate the performance of orthodontic treatment (Fig 2) Cephalometric evaluation indicated important skeletal disharmony, with ANB angle equal to $-1^{\circ}$ (SNA $=86^{\circ}$ and $\mathrm{SNB}=87^{\circ}$ ), with good mandibular growth in the vertical direction $\left(\mathrm{SN}-\mathrm{GoGn}=32^{\circ}\right)$, highlighting the balanced facial aspect. Upper and lower incisors were slightly tipped buccally (these observations can be better evaluated on Figure 3 and Table 1).

\section{Treatment objectives and alternatives}

It is possible to present, as the main objectives for treatment of the reported patient, by its order of importance: Expansion of the upper arch, eliminating premature contacts and correcting the posterior crossbite; by extracting lower third molars, to allow for the distalization of lower teeth, with the objective of correcting Class III malocclusion and establish adequate intercuspation. Since he showed a slight anterior open bite, precautions with vertical control were set during the distalization of the lower teeth.

The possibility of surgical treatment was not considered, because of the reduced magnitude of skeletal discrepancy, as well as because of the absence of adverse features on facial esthetics that could justify such an approach.

\section{Treatment}

Despite skeletal discrepancy $\left(\mathrm{ANB}=-1^{\circ}\right)$, the case presented treatment feasibility to be just orthodontic. By examining him in detail, it was noticed that the presence of anterior open bite was conditioned to premature contacts on the posterior region, due to the crossbite. 

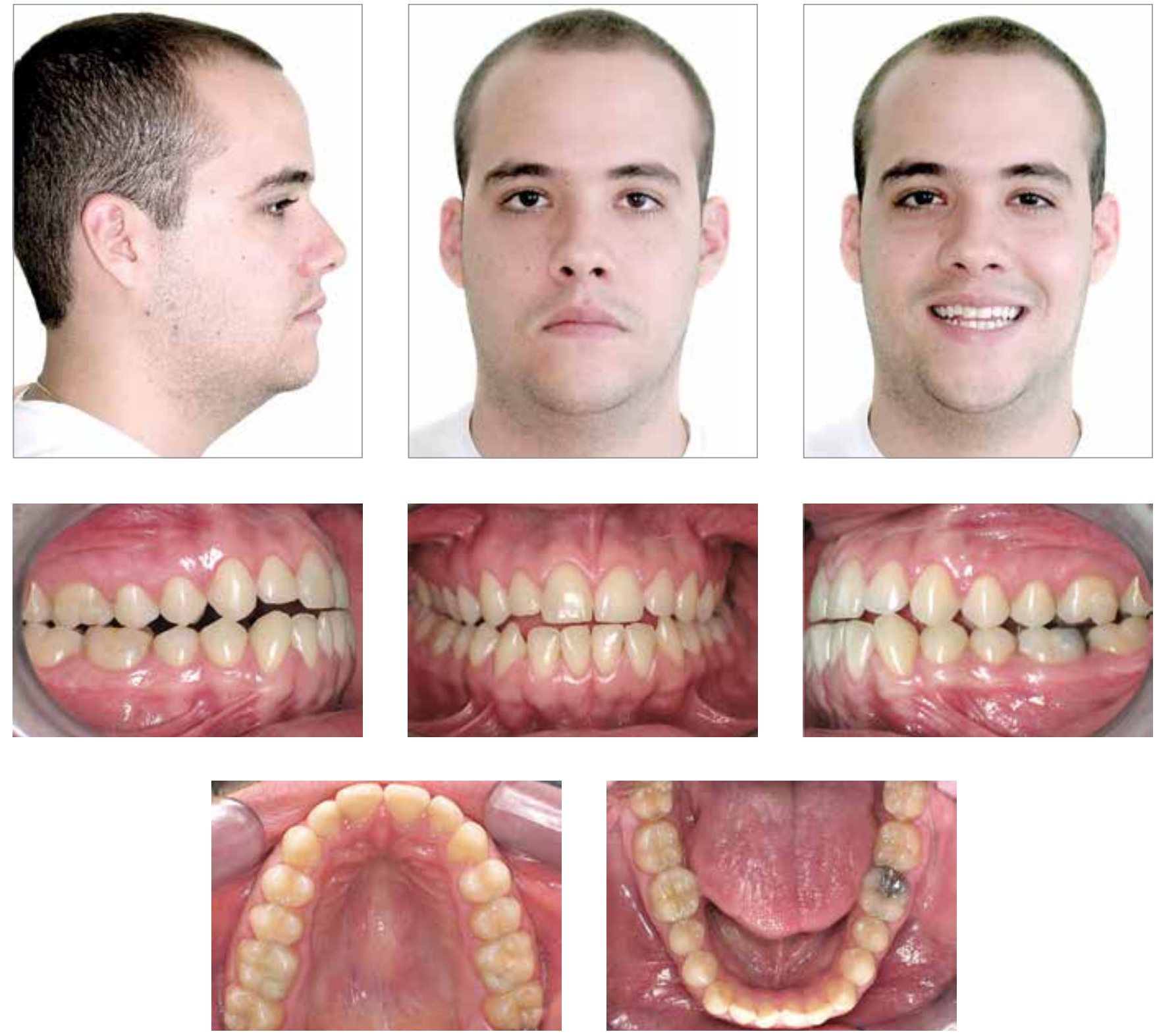

Figure 1 - Facial and intraoral initial photographs.

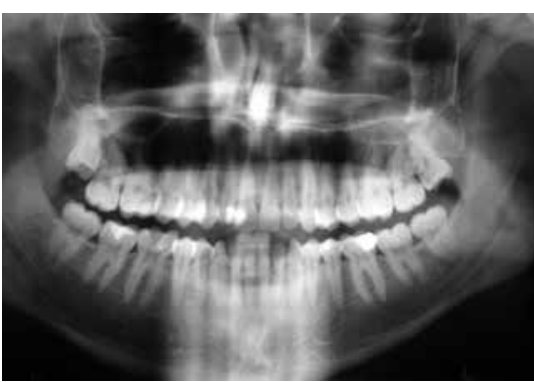

Figure 2 - Initial panoramic radiograph.
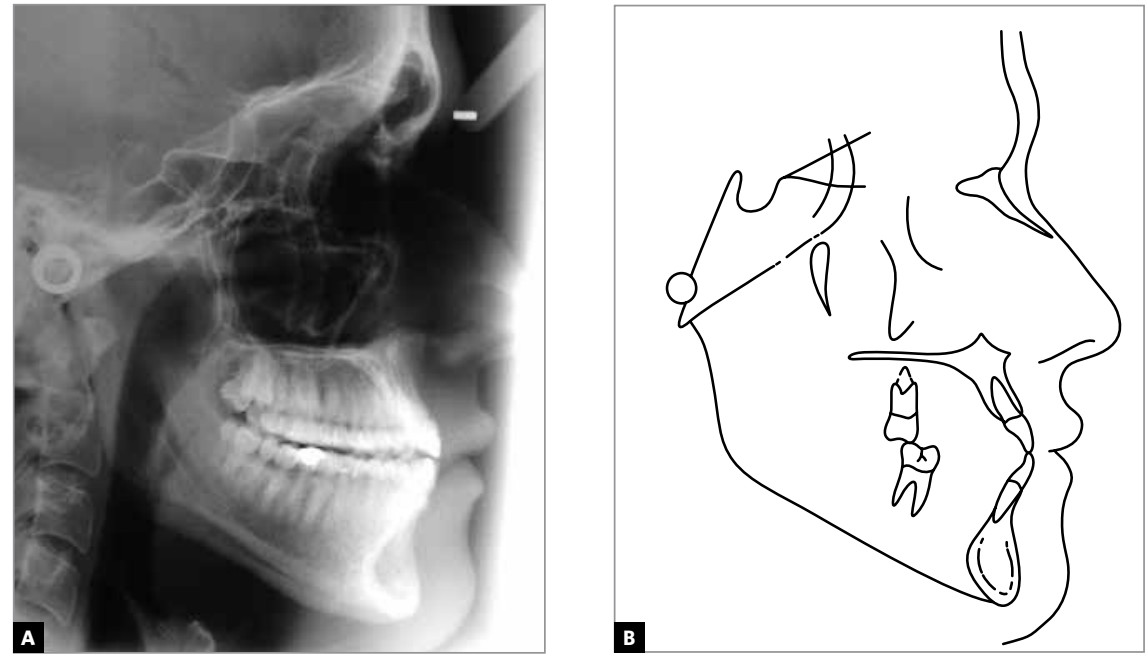

Figure 3 - Initial lateral cephalometric radiograph (A) and tracing (B). 
So, the first treatment step would be to expand the upper arch, to eliminate transverse discrepancy, in order to obtain a more adequate evaluation on the real magnitude of the Class III, because it was believed that, in part, the latter was due to functional accommodation of the mandible.

The treatment itself was started with slow expansion of the upper arch (1/4 turn in alternate days, during 30 days) with a Hyrax type expander, with the objective to improving arch form, making it compatible, in the transverse dimension, with the lower arch. Three months after the correction of the posterior crossbite, the Hyrax expander was removed and then standard Edgewise 0.022 x 0.028-in slot metal brackets, with no torque or angulations, were installed.

In the lower arch, extractions of \#38 and \#48 were requested, with posterior appliance placement, with the exception of canines and incisors - because if they were included, it would cause undesirable projection of these teeth, due to the presence of crowding.

Once alignment and levelling of upper and lower arches (with exception of teeth \#31, \#32, \#33, \#41, \#42, $\# 43$ ), was concluded, the improvement of coordination was beginning to be noticed on the anterior region, with the reduction of open bite (Fig 5). At this moment, $0.018 \times 0.025$-in steel arches were placed on both arches.

Class III mechanics (150 g/side) was started, attached to teeth \#17, \#27 and on long sliding jigs on the lower arch, extending from the tubes of teeth \#37 and \#47 to the mesial of lower canines (Figs 5 and 6). With that, the objective of this step was to use all the anchorage of the upper arch to distalize, tooth by tooth, the lower arch, by the means of light forces, in order to minimize collateral effects - such as the counterclockwise rotation of the upper occlusal plane. Thus the treatment was conducted until the correction of molar relation and the attainment of space on anteroinferior region. Then the canines and incisors were included, performing once more the alignment and levelling of the lower arch.

" Vertical control: At the moment the arches were found stable with rectangular $0.018 \times 0.025$-in wires, a specific intermaxillary Class III mechanics was started, with the objective of promoting refinement on the intermaxillary correction obtained be- fore with the sliding jigs. Now, with heavier forces (150 g/ side), and the curve of Spee accentuated on the upper arch, reverse on the lower arch, and vertical elastics in the anterior region (150 g), the ideal conditions for adequate finishing were established (Fig 4). At this moment, the only limitation was restricted to the patient's agreement on using the elastics. The accentuated and reverse curves of Spee, respectively on the upper and lower arches, along with anterior vertical elastics, had the function of promoting efficient vertical control, with the closing of the anterior open bite due to the rotation of the upper occlusal plane with a clockwise direction and of the lower occlusal plane with a counterclockwise direction, which happened as expected (Fig 5).

The option for this kind of mechanics was because of the favorable dental and facial features presented by the patient. That would not be a good Indication for patients with excessive vertical pattern, once that, if the patient does not collaborate with the use of elastics, the effects on the occlusion may be disastrous and of harder resolution. Then, upper and lower $0.019 \times 0.026$-in stainless steel arches, were made with individualized bends, for proper finishing. The retention on the upper arch was accomplished with a wraparound and, on the lower one, with an intercanine fixed retainer (0,032-in).

\section{Analysis of results}

The main objectives of the treatment were accomplished, establishing an adequate dental relationship, with direct repercussion on the esthetics of the smile (Fig 7). As expected, no alteration on facial esthetics was not found. The patient was extremely cooperative, concerning the use of the proposed mechanics. With the dental alterations, the ANB angle was maintained, and there was a buccal inclination of upper incisors and retroinclination of lower ones, as well as efficient vertical control, with maintenance of the mandibular plane (Figs 8, 9, 10 and Table 1).

At the end of treatment, it was possible to observe the achievement of a Class I occlusion on canines and molars, and correction of anterior open bite, as well as adequate alignment and levelling (Fig 7). 

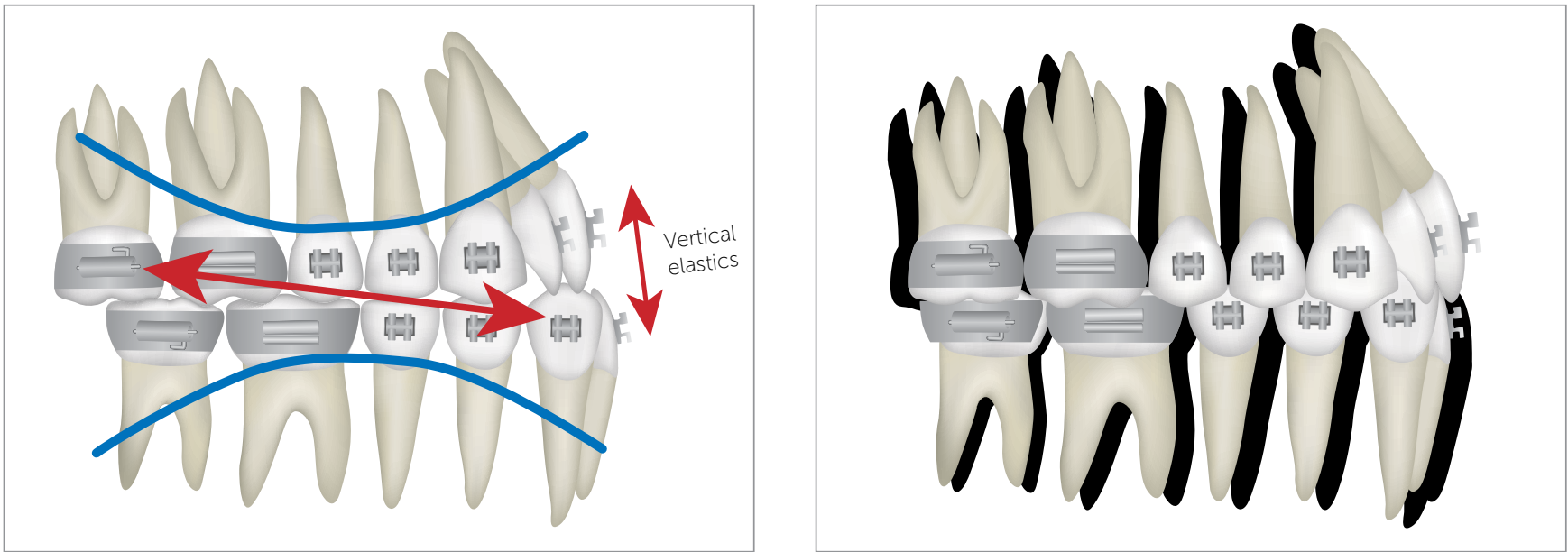

Figure 4 - Illustration of Class III mechanics use of intermaxillary elastics, reverse curve of Spee on the lower arch and accentuated Curve of Spee on the upper arch, associated to vertical elastics in the anterior region.
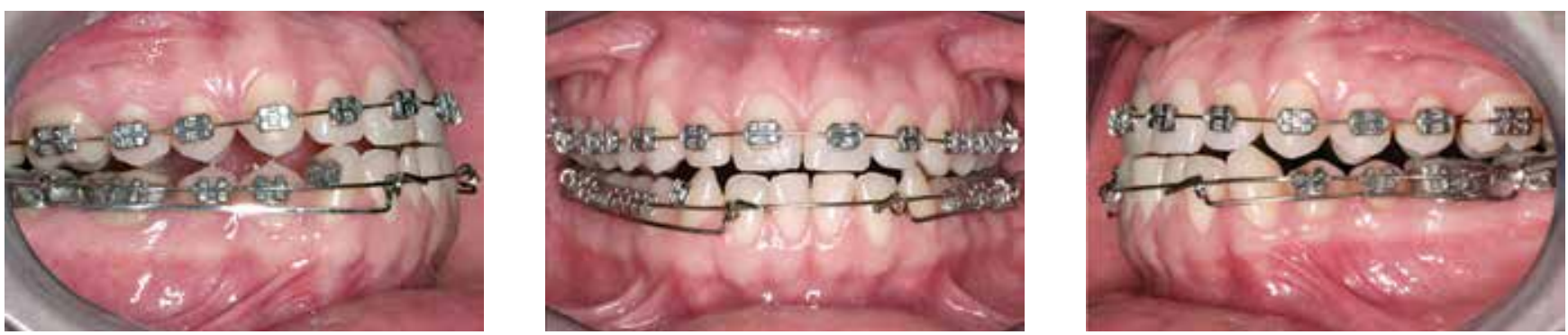

Figure 5 - Initial step of treatment. Class III mechanics with long sliding jigs (lower arch).
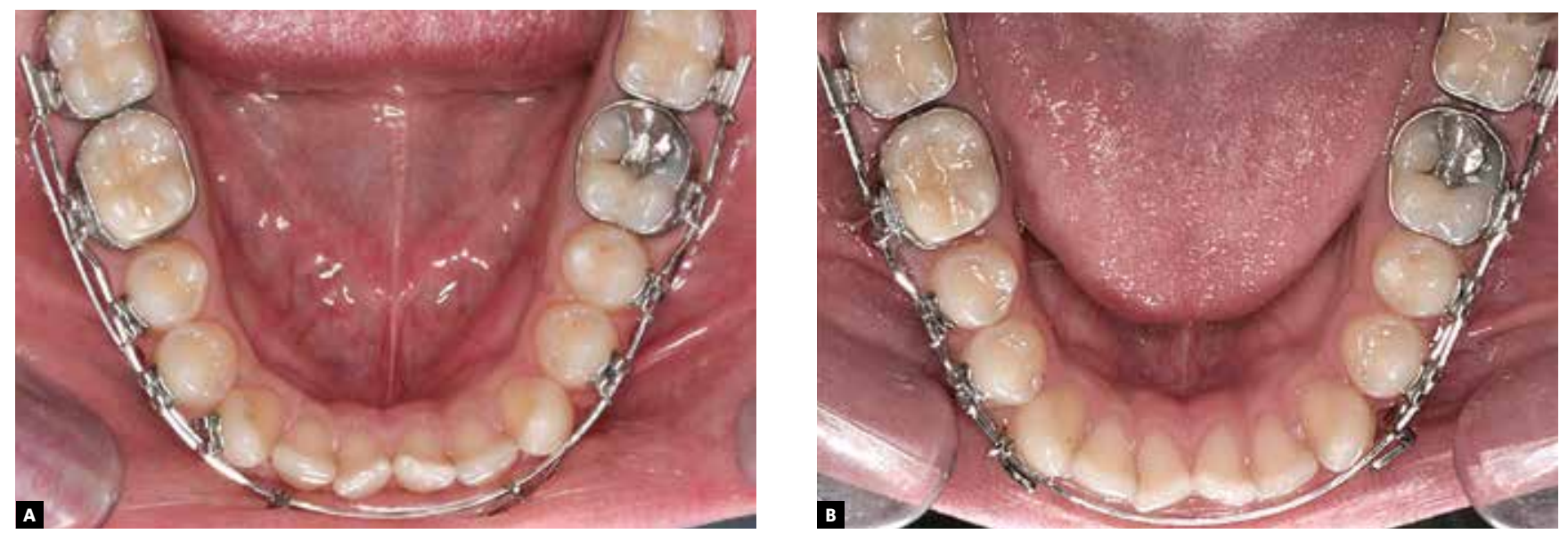

Figure 6 - A) Beginning of Class III mechanics. B) After 40 days, spaces between the upper teeth can be noticed. 

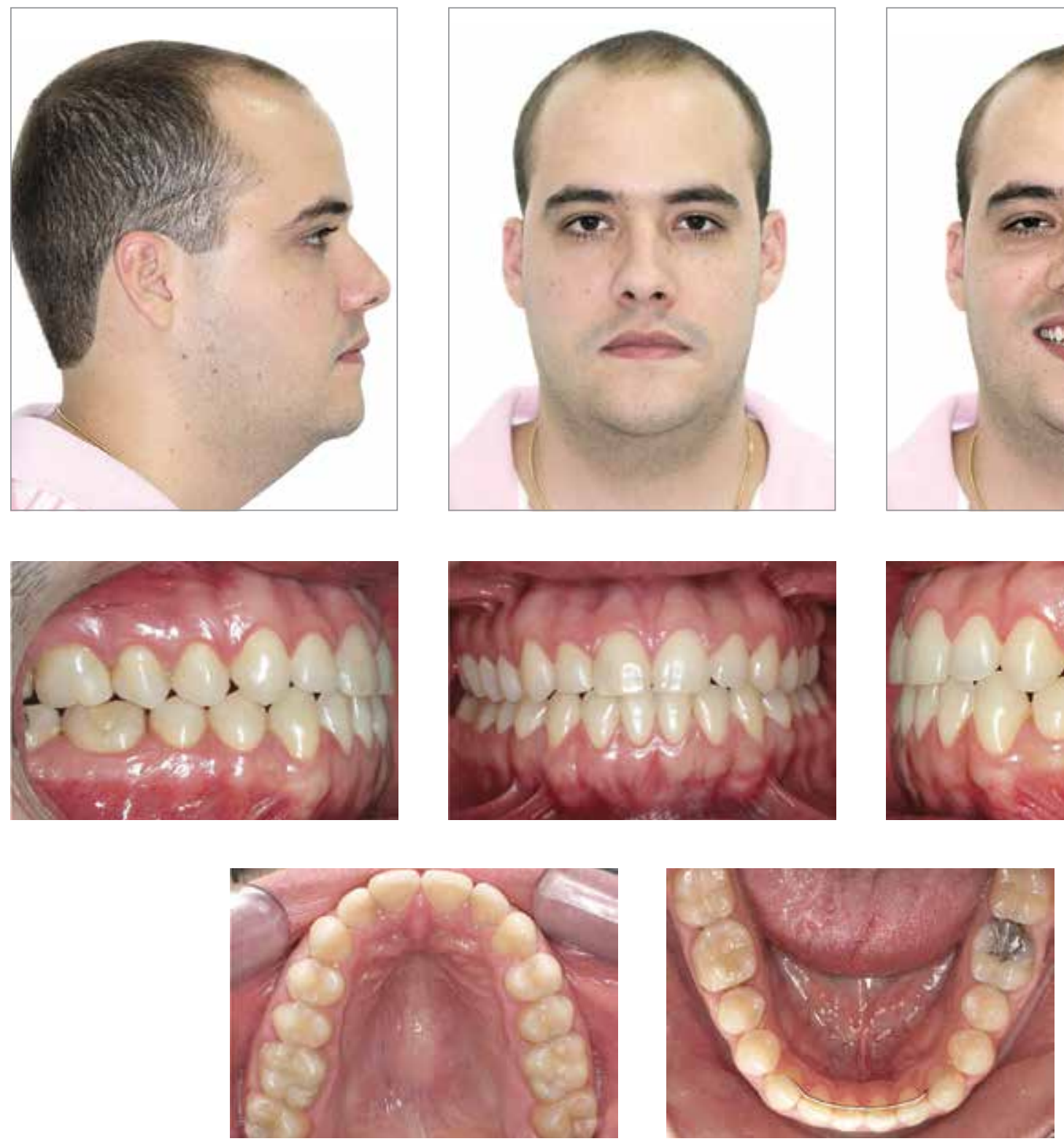

Figure 7 - Final facial and intraoral photographs.

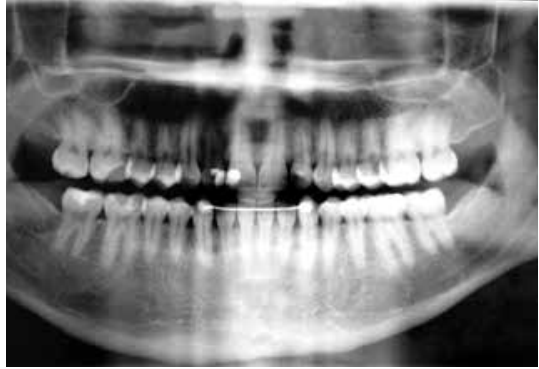

Figure 8 - Final panoramic radiograph.

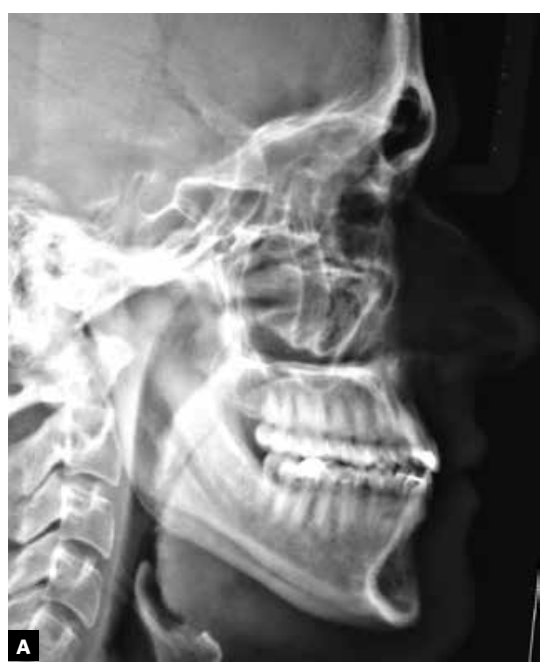

Figure 9 - Final lateral cephalometric radiograph $(\mathbf{A})$, and cephalometric tracing $(\mathbf{B}$

B
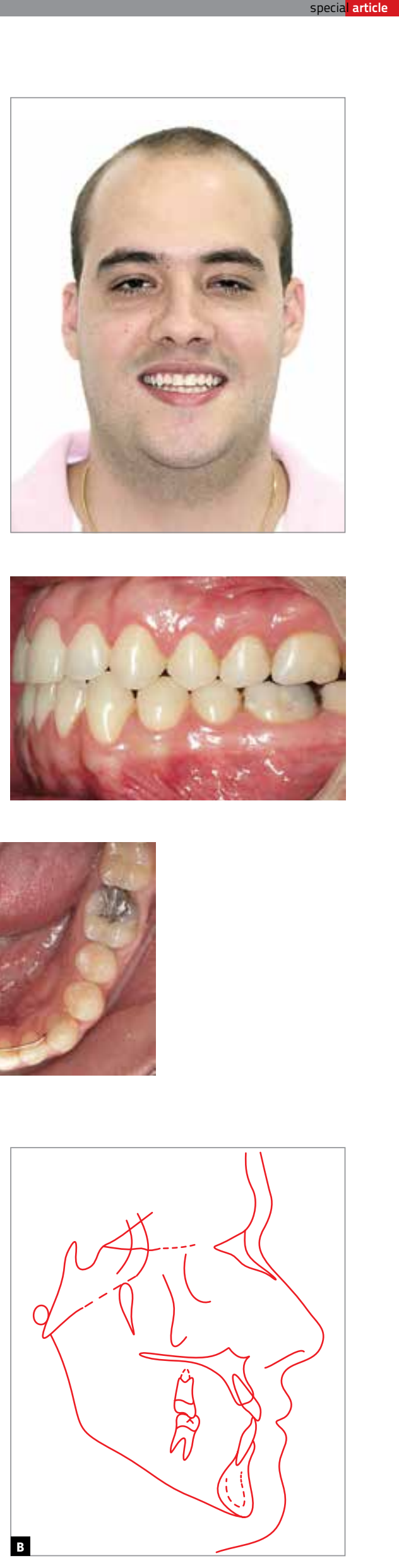

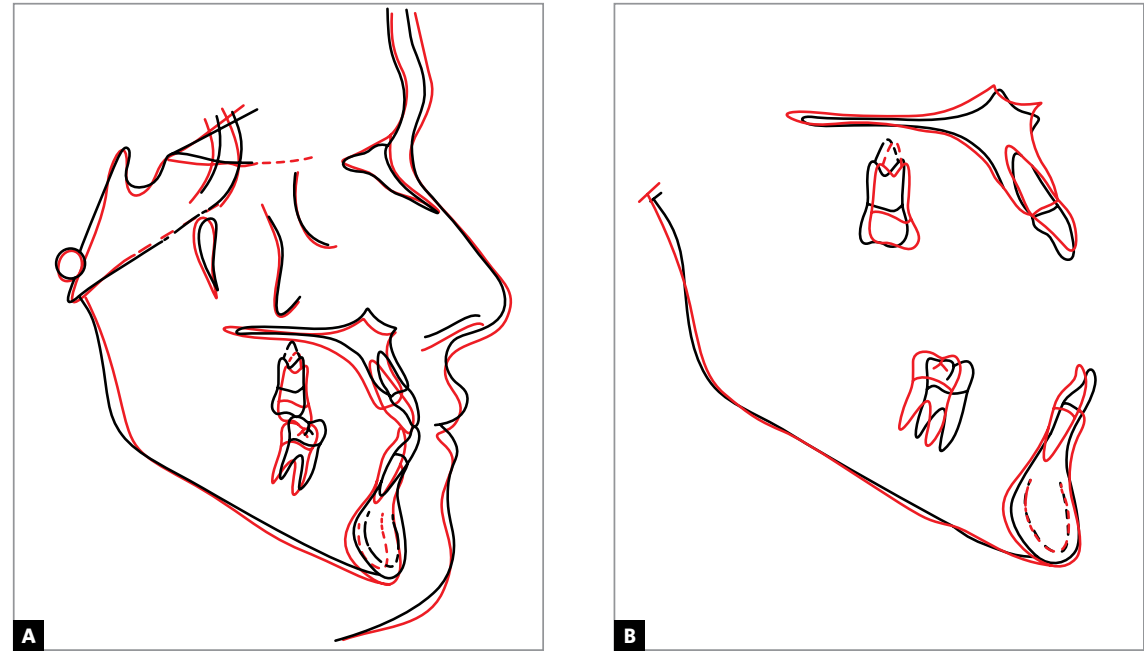

Figure 10 - Total (A) and partial (B) superimpositions of initial (black) and final (red) cephalometric tracings.

Table 1 - Summary of cephalometric measurements

\begin{tabular}{|c|c|c|c|c|c|c|}
\hline & \multicolumn{2}{|c|}{ Measures } & \multirow{2}{*}{$\begin{array}{c}\text { Normal } \\
82^{\circ}\end{array}$} & \multirow{2}{*}{$\begin{array}{c}\text { A } \\
86^{\circ}\end{array}$} & \multirow{2}{*}{$\begin{array}{c}\text { B } \\
84^{\circ}\end{array}$} & \multirow{2}{*}{$\begin{array}{c}\text { A/B diff } \\
2\end{array}$} \\
\hline \multirow{8}{*}{ Skeletal pattern } & SNA & (Steiner) & & & & \\
\hline & SNB & (Steiner) & $80^{\circ}$ & $87^{\circ}$ & $85^{\circ}$ & 2 \\
\hline & ANB & (Steiner) & $2^{\circ}$ & $-1^{\circ}$ & $-1^{\circ}$ & 0 \\
\hline & Convexity angle & (Downs) & $0^{\circ}$ & $-5^{\circ}$ & $-5^{\circ}$ & 0 \\
\hline & $Y$ axis & (Downs) & $59^{\circ}$ & $58^{\circ}$ & $58^{\circ}$ & 0 \\
\hline & Facial angle & (Downs) & $87^{\circ}$ & $86^{\circ}$ & $86^{\circ}$ & 0 \\
\hline & SN-GoGn & (Steiner) & $32^{\circ}$ & $32^{\circ}$ & $33^{\circ}$ & 1 \\
\hline & FMA & (Tweed) & $25^{\circ}$ & $27^{\circ}$ & $28^{\circ}$ & 1 \\
\hline \multirow{6}{*}{ Dental pattern } & IMPA & (Tweed) & $90^{\circ}$ & $92^{\circ}$ & $85^{\circ}$ & 7 \\
\hline & 1.NA (degrees) & (Steiner) & $22^{\circ}$ & $24^{\circ}$ & $28^{\circ}$ & 4 \\
\hline & 1-NA (mm) & (Steiner) & $4 \mathrm{~mm}$ & 11 mm & $9 \mathrm{~mm}$ & 2 \\
\hline & I.NB (degrees) & (Steiner) & $25^{\circ}$ & $30^{\circ}$ & $22^{\circ}$ & 8 \\
\hline & 1-NB (mm) & (Steiner) & $4 \mathrm{~mm}$ & $9 \mathrm{~mm}$ & $6 \mathrm{~mm}$ & 3 \\
\hline & $\frac{1}{1}$-Interincisal angle & (Downs) & $130^{\circ}$ & $126^{\circ}$ & $130^{\circ}$ & 4 \\
\hline \multirow{2}{*}{ Profile } & Upper Lip - S Line & (Steiner) & $0 \mathrm{~mm}$ & $-1 \mathrm{~mm}$ & $-3 \mathrm{~mm}$ & 2 \\
\hline & Lower Lip - S Line & (Steiner) & $0 \mathrm{~mm}$ & $-3.5 \mathrm{~mm}$ & $-3.5 \mathrm{~mm}$ & 0 \\
\hline
\end{tabular}

\section{PATIENTS WITH ADVERSE VERTICAL FACIAL PATTERN}

\section{Case 2 - Class III with anterior open bite} and mandibular asymmetry, treated with extractions (\#15, \#25, \#34, \#44).

" Vertical control: Extraoral forces with high pull headgear (J-hooks).

\section{History and etiology}

The patient, 20 years old, presented for initial exam in a good general state of health. Her main complaint was related to the presence of anterior open bite and facial asymmetry, with mandibular deviation to the left side. Facial esthetics seemed to be a concern to the patient, due to the asymmetry caused by laterognathism (Fig 11). With more detailed examination of the occlusion, a real mandibular deviation to the left side was noticed, generated, probably, by asymmetric growth, and not by a purely functional deviation. Although, according to the mother, there was no reference to Class III on her family medical history, the peculiarities involved pointed to a multifactorial etiology. 

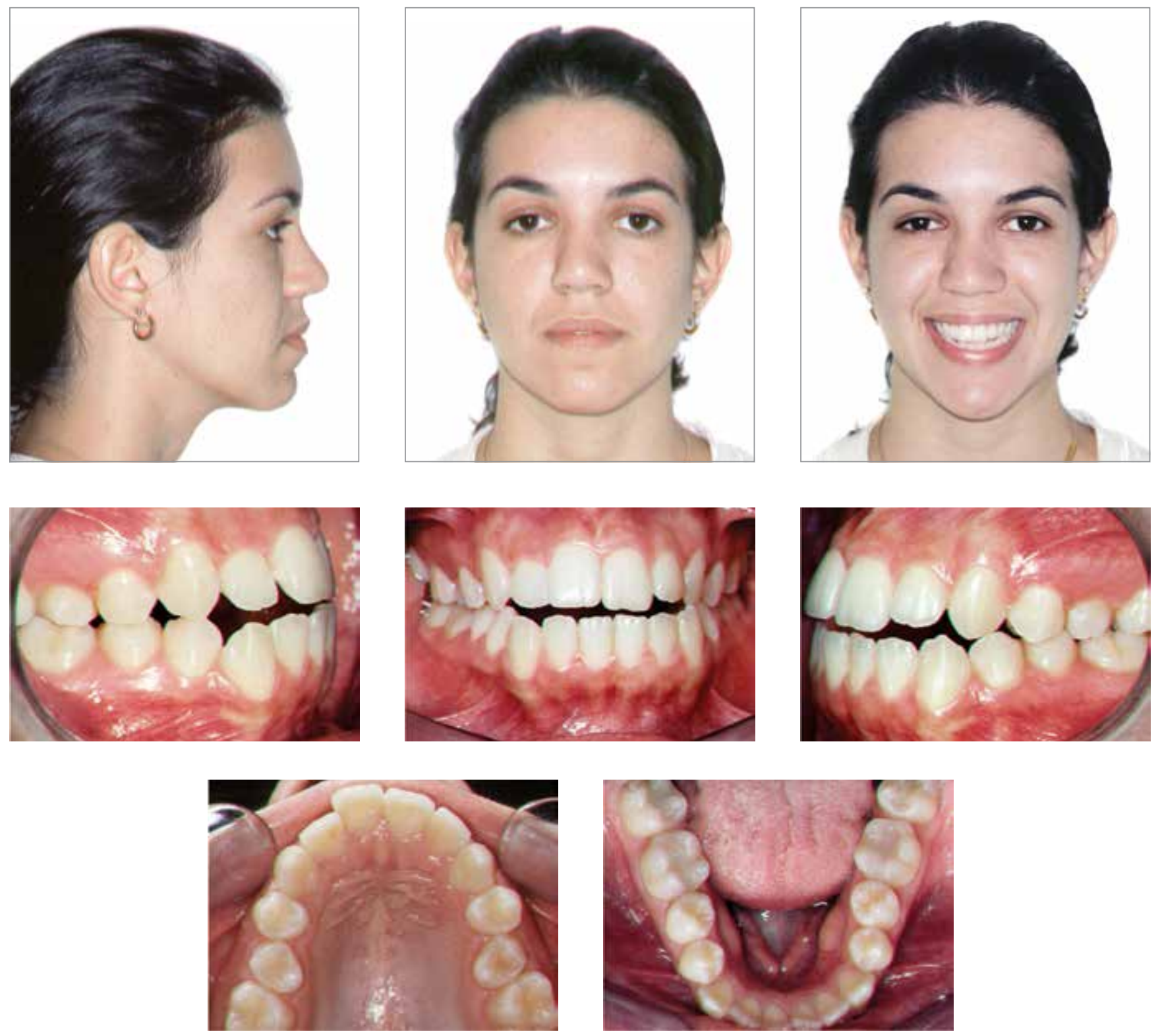

Figure 11 - Initial facial and intraoral photographs

\section{Diagnosis}

Regarding facial features, she presented a dolichocephalic facial type, with a convex profile, inferior facial third slightly increased, lip competence, and presence of asymmetry due to mandibular deviation to the left. The lips were protruded, the lower one being slightly on front of the upper one (Fig 11).

In the dental aspect, she presented an Angle Class III malocclusion, with anterior open bite, $1 \mathrm{~mm}$ overjet, with buccal tipping of upper and lower incisors, characterizing a dentoalveolar double protrusion. Yet, an atresic upper arch was noticed, with a slight anterosuperior crowding and rotation of teeth \#15 and \#25.
The lower midline was deviated 2,5 $\mathrm{mm}$ to the left, but was coincident with the center of the chin, characterizing a skeletal deviation, but not a dental one (Fig 11).

The panoramic radiograph analysis did not show any significative alteration that could contraindicate the performance of orthodontic treatment (Fig 12). Cephalometric evaluation indicated important skeletal disharmony, with $\mathrm{ANB}=-2^{\circ}\left(\mathrm{SNA}=78^{\circ}\right.$ and $\mathrm{SNB}=$ $80^{\circ}$ ), with a poor mandible with a vertical growth direction $\left(\mathrm{SN}-\mathrm{GoGn}=39^{\circ}\right)$, aggravating the vertical facial aspect. The maxilla and the mandible were slightly retruded in relation to the cranial base (this can be better evaluated on Fig 13 and Table 2). 


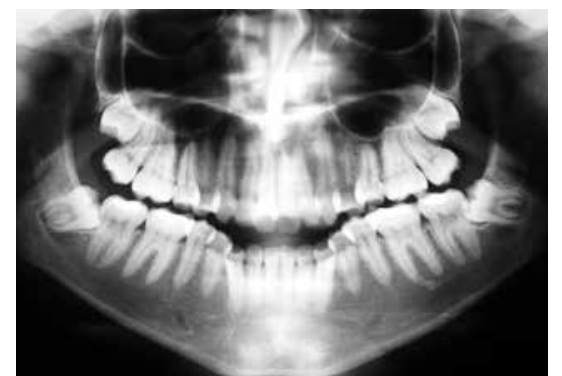

Figure 12 - Initial panoramic radiograph

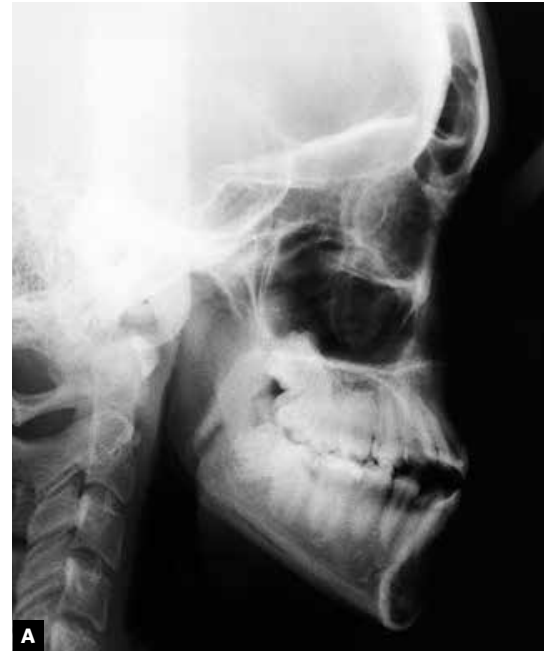
Figure 13 - Initial lateral cephalometric radiograph $(\mathbf{A})$ and cephalometric tracing (B)

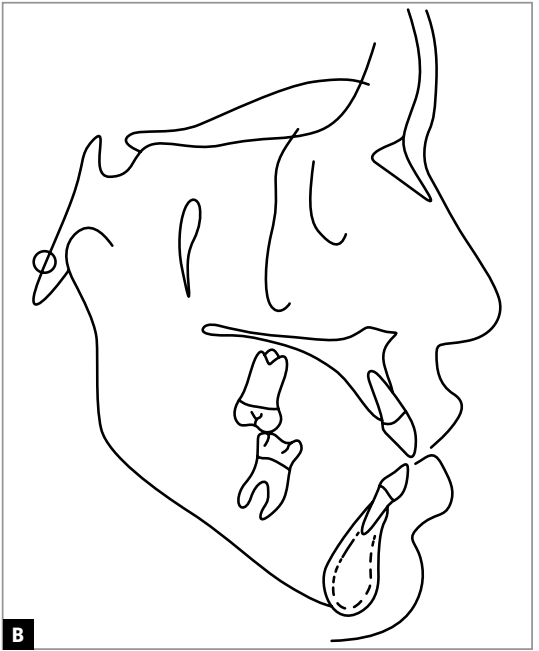

B

\section{Treatment objectives and alternatives}

With no doubt, the best treatment option included a surgical approach with asymmetric mandibular setback; however, this alternative was completely discarded by the patient and her parents. It was also proposed as treatment alternative a compensatory orthodontic treatment, with extraction of the second upper premolars and the first lower premolars, and the use of extraoral headgear (high-pull J-hook) on the lower arch during the retraction of canines and incisors. The achievement of this resource was pointed as indispensable for treatment success. With its use an efficient vertical control and maintenance of lower occlusal plane would be achieved, promoting a counterclockwise rotation, fundamental for the correction of the anterior open bite. At the end of treatment, an adequate occlusion was expected, with absence of the exposure of lower incisors in the smile, which would contribute to camouflage the mandibular asymmetry and to give the smile a pleasant esthetics.

\section{Treatment}

Facing the refusal of performing a combined orthodontic and surgical treatment, a compensatory orthodontic treatment was done, with second upper premolars and first lower premolars extracted. Associated with that, the use of extraoral high-pull headgear (J-hook) on the lower arch, in order to promote efficient vertical control during treatment, specifically during canine and incisor retraction (Fig 14).
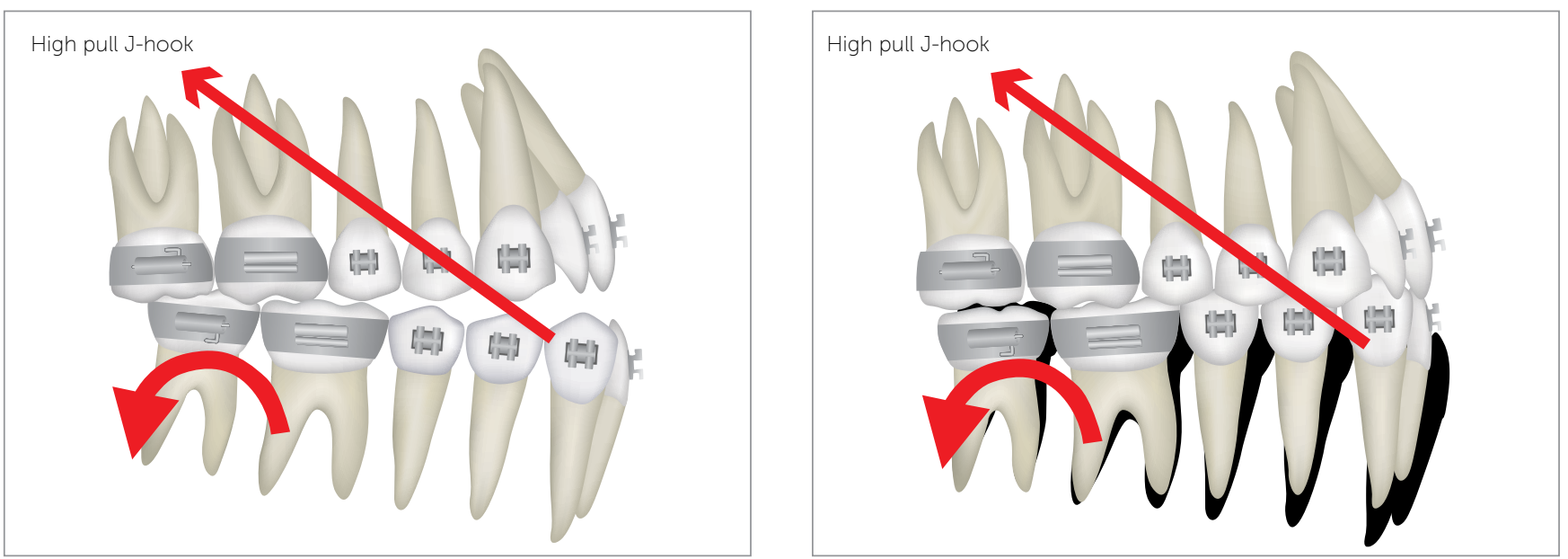

Figure 14 - Illustration of Class III mechanics employed for vertical control, anchored on J-hooks in the lower arch. 
In the upper arch a slow expansion was performed (1/4 turn on alternate days, during 30 days) with a Hyrax expander, with the objective of improving arch form, making it compatible in the transverse direction with the lower arch. Then, standard metal brackets, with no torque or angulations, slot $0.022 \mathrm{x}$ 0.028-in, Edgewise system were placed.

In the lower arch, apart from the fixed appliances, a high pull headgear (J-hook) was used.

After the removal of the Hyrax device, extractions of teeth \#15 and \#25 were requested, and then the alignment and leveling was performed, with 0.014-in, 0.016-in, 0.018-in and 0.020-in stainless steel arches, respectively. In the lower arch, initially the extractions of teeth \#34 and \#44 were requested and then the alignment and leveling was performed, with 0.014-in, 0.016-in, 0.018-in and 0.020 -in sequential stainless steel wires. With the $0.018 \times 0.025$-in rectangular wire, the J-hook headgear was adapted on the lower arch, with high pull direction $(150 \mathrm{~g} /$ side $)$. The patient was instructed to use it for at least $12 \mathrm{~h} /$ day. It was directly anchored on the arch, hooked to the canines, working as jigs, with the objective of distalizing the lower canines and, at the same time, due to the high pull, promote efficient vertical control, generating a rotation of the lower occlusal plane in the counterclockwise direction - which was favorable for the closure of the open bite (Fig 14). Due to the asymmetry and the greater need for distal movement of tooth \#43, after distalization of tooth \#33, the J-hook was anchored to a hook welded to the arch between teeth \#32 and $\# 33$, while the right side would continue to play the role of a jig, moving tooth \#43.

Meanwhile, in the upper arch, space closure would be executed in a reciprocal way, with the objective of enabling posterior anchorage loss, together with retraction and uprighting of the incisors, and consequent closure of the open bite.

Then, upper and lower $0.019 \times 0.026$-in stainless steel arches, with bends and torques were made, individualized, as needed for adequate finishing (Fig 15). The retention on the upper and lower arches, was done with wraparound type removable appliances.

\section{Analysis of results}

The main objectives of the treatment were accomplished, establishing an adequate dental relationship, with important repercussion on the general esthetics of the face, and, in a specific way, significative improvement on the smile, with the absence of exposure lower teeth (Fig 15), collaborating for mandibular asymmetry camouflage. It is worth to highlight that a preponderant factor for the success of the treatment was patient collaboration, with the use of extraoral mechanics, resulting in excellent vertical control. With the dental alterations, there was a significative change on the ANB angle, from $-2^{\circ}$ to $3^{\circ}$ (Figs 17, 18 and Table 2 ).

That fact can be attributed to remodeling of the alveolar processes on lower and upper anterior regions, as response to the retraction mechanics employed. There was also significative improvement on the inclination on lower and upper incisors, with a decrease of 1-NA from $30^{\circ}$ to $20^{\circ}$, and from 1-NB from $32^{\circ}$ to $24^{\circ}$, effecting directly on the closure of the open bite and on the improvement of facial profile (Figs 17, 18, and Table 2). A Class I occlusion relationship was achieved on canines and molars, and the anterior open bite was corrected. Alignment, leveling, and inclination correction were successfully achieved (Fig 7). 

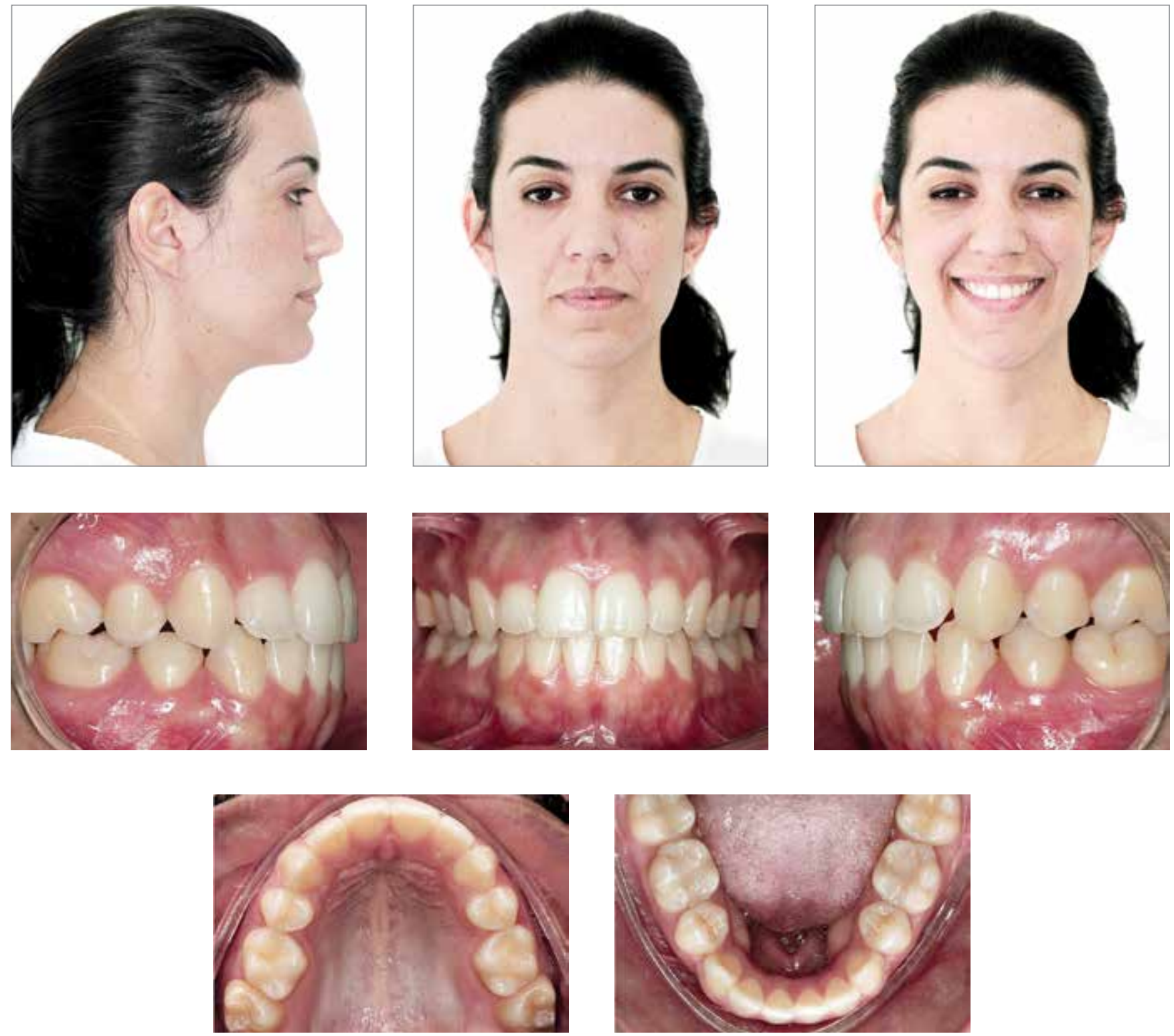

Figure 15 - Final facial and intraoral photographs.

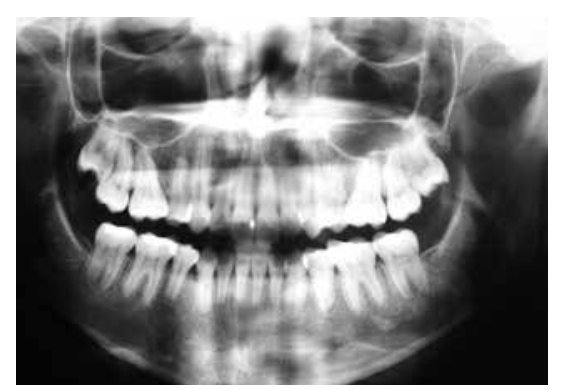

Figure 16 - Final panoramic radiograph.
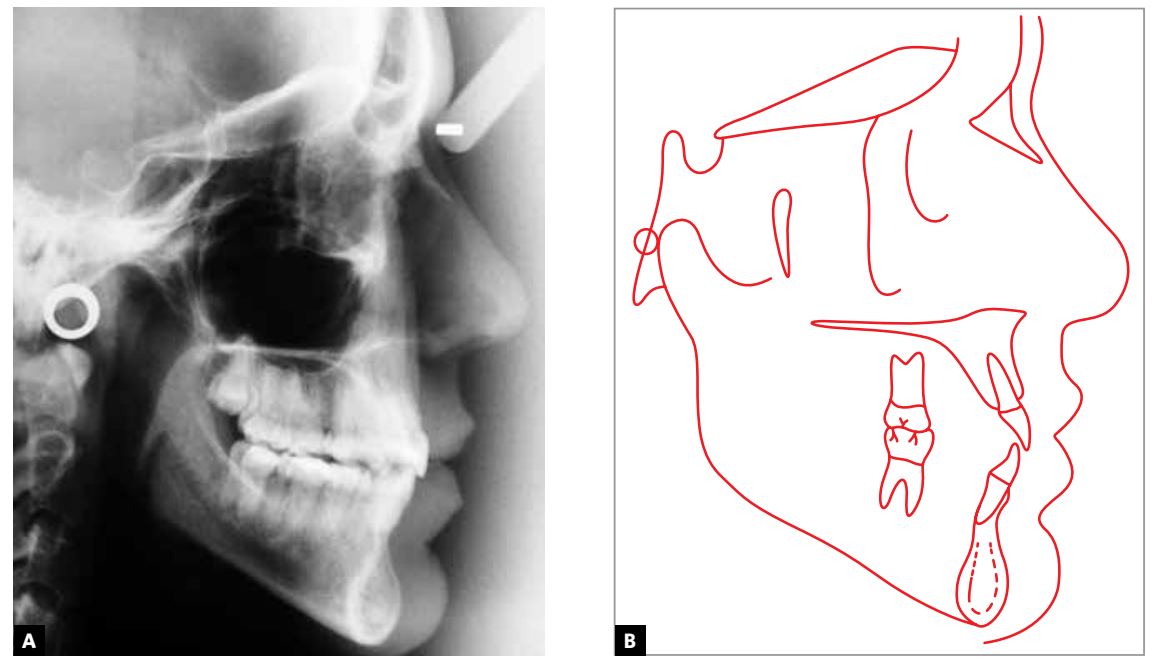

Figure 17 - Final lateral cephalometric radiograph $(\mathbf{A})$ and cephalometric tracing (B) 

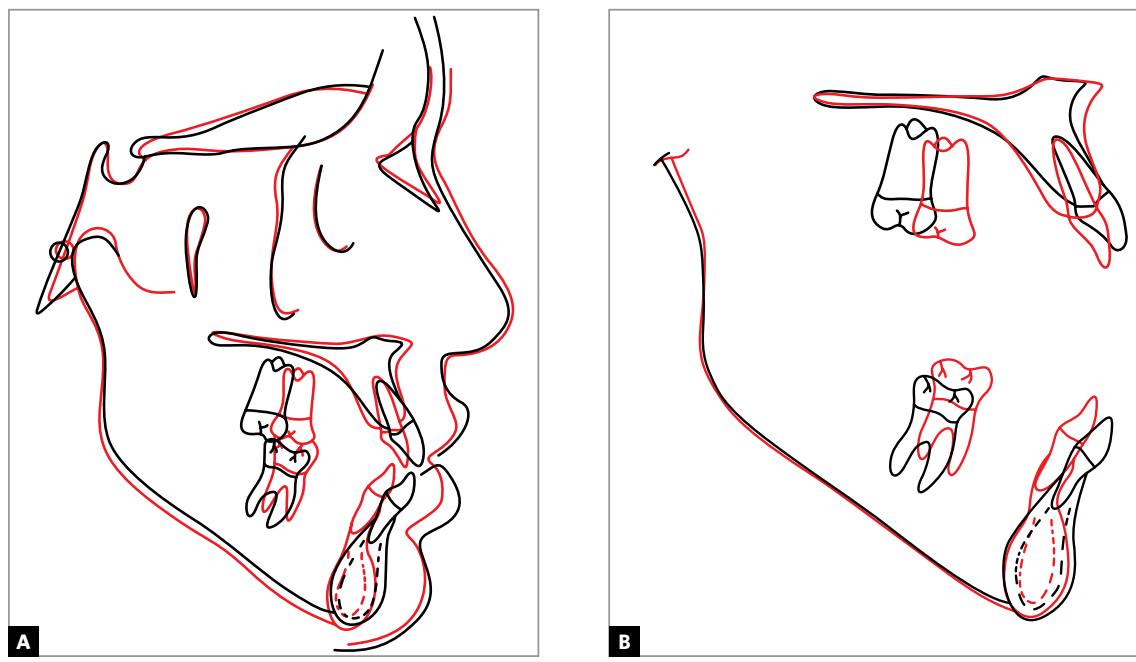

Figure 18 - Total (A) and partial (B) superimpositions of initial (black) and final (red) cephalometric tracings.

Table 2 - Summary of cephalometric measurements.

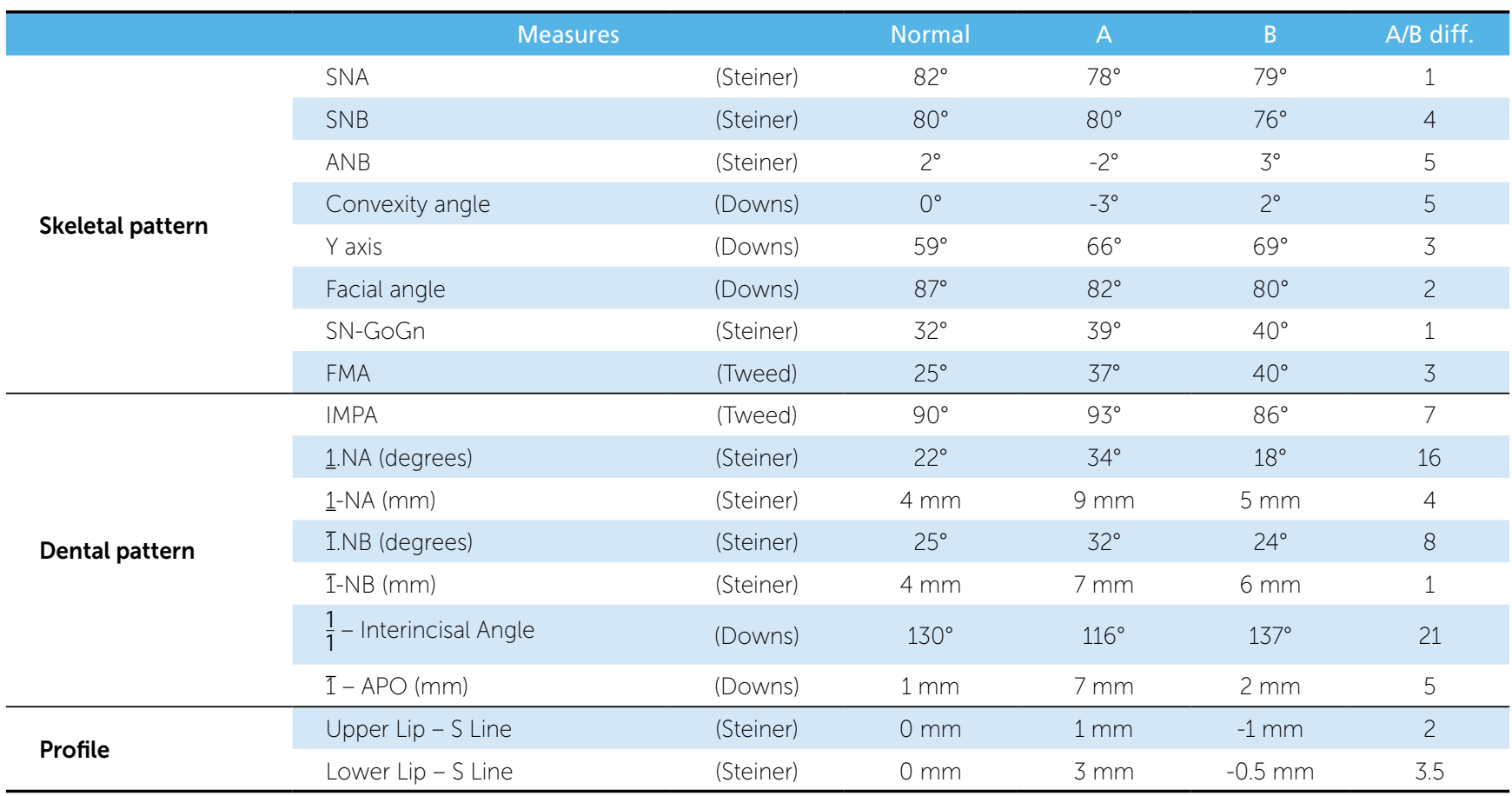

Case 3 - Class III with anterior open bite treated with extractions (\#38, \#48)

" Vertical control: Skeletal anchorage

\section{History and etiology}

The patient, 29 years old, presented for initial exam in a good general state of health. His main complaint was related to the presence of anterior open bite, associated with masticatory difficulty. Facial esthetics did not seem to be a concern (Fig 19). With more detailed examination of the occlusion, a disharmony was noticed between the maxilla and the mandible, on the anteroposterior direction. There was reference to Class III on his family medical history.

\section{Diagnosis}

Regarding facial features, he presented a dolichocephalic facial type, with a convex profile, lower facial 

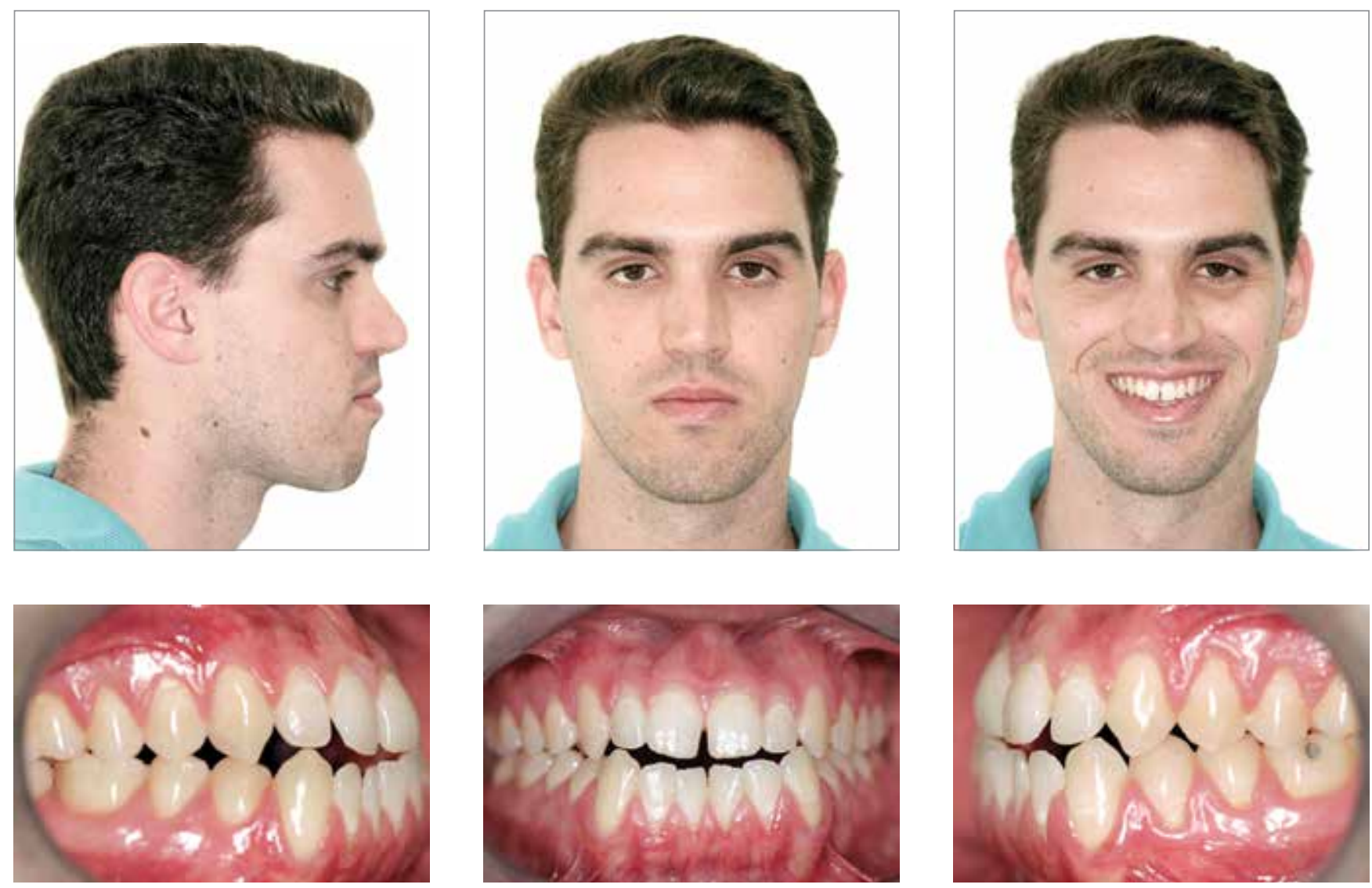

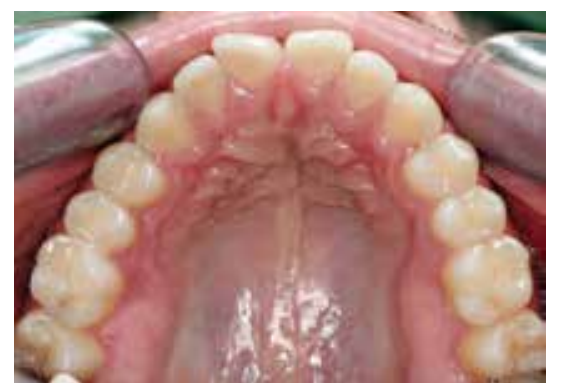

Figure 19 - Initial facial and intraoral photographs

third largely increased and lip incompetence at rest. The lips presented a unbalanced relation, the lower being in front of the upper. He presented adequate exposure of upper incisors, when smiling (Fig 19).

Regarding the dental aspect, he had an Angle Class III malocclusion, with anterior open bite $(2 \mathrm{~mm})$, and a $-2 \mathrm{~mm}$ overjet. Also, an ample upper arch was noticed, with rotations of central incisors and interincisal diastema. There was a reverse curve of Spee on the lower arch, with significative unevenness between posterior and anterior segments of the arch; upper and lower occlusal planes were divergent, and midlines were coincident (Fig 19). The presence of countless gingival recessions was, probably, related to the inad-

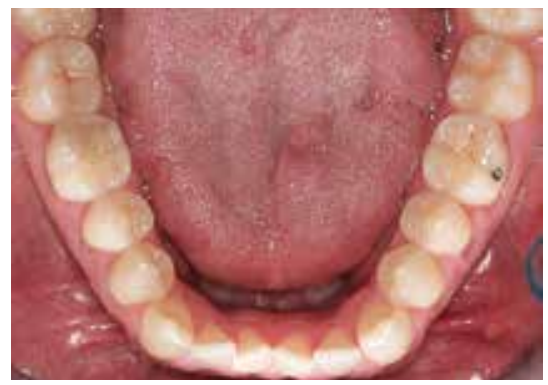

equate and traumatic form with which the patient performed brushing, conjugated to extremely fine periodontal profile, especially on the lower incisor region.

The panoramic radiograph analysis did not show any significant alteration that could contraindicate the performance of orthodontic treatment (Fig 20). Cephalometric evaluation indicated important skeletal disharmony, with $\mathrm{ANB}=-1^{\circ}\left(\mathrm{SNA}=79^{\circ}\right.$ and $\left.\mathrm{SNB}=80^{\circ}\right)$, with poor mandibular growth in the vertical direction $\left(\mathrm{SN}-\mathrm{GoGn}=34^{\circ}\right)$, highlighting the vertical hyperdivergent facial aspect. Upper incisors were tipped buccally and lower ones were vertical, in relation to the basal bone (those observations can be better evaluated on Fig 21 and Table 3). 


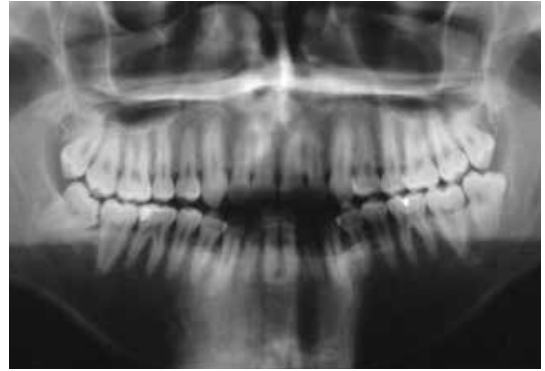

Figure 20 - Initial panoramic radiograph.
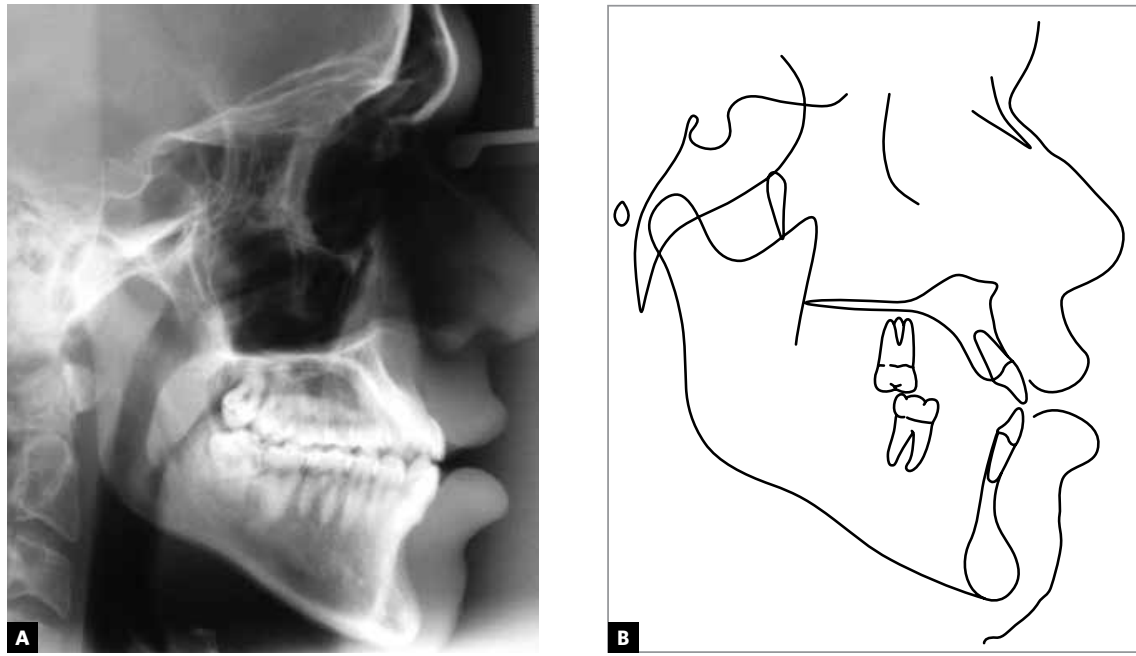

Figure 21 - Initial lateral cephalometric radiograph $(\mathbf{A})$ and tracing (B)

\section{Treatment objectives and alternatives}

Initially, orthosurgical treatment, probably with need of maxillomandibular manipulation, was presented as the only option to establish adequate esthetic and functional patterns. The surgical alternative was completely discarded by the patient. As another alternative, a compensatory orthodontic treatment was suggested with extraction of lower third molars, the use of skeletal anchorage on the upper arch (mini-implants) to support Class III intermaxillary mechanics, in order to reproduce the system of directional forces presented by Tweed-Merrifield, during distal lower tooth movement. ${ }^{12}$ The achievement of this mechanic was pointed as indispensable for treatment success. With its use, efficient vertical control and maintenance of inferior occlusion plane would be achieved, promoting its rotation in a counterclockwise direction, fundamental for the correction of the anterior open bite. At the end of the treatment, an adequate occlusion was expected to be found, with counterclockwise rotation of the lower occlusal plane and decrease of lower incisor exposure in the smile. Periodontal control, associated with adequate brushing technique, was fit to minimize progression of recession, which was also part of the objectives.

\section{Treatment}

Even with the absence of complaint about facial esthetics, it was clear that the best option for the treatment would be the combination of orthodontics with orthognathic surgery. The patient readily manifested his aversion to surgery, questioning the alternatives. After careful analysis of the case, a compensatory orthodontic treatment was proposed, with the purpose of offering satisfactory occlusion with no worries about changes in the facial aspect. The greatest concern on the elaboration of the treatment plan was due to the need of efficient vertical control, because of the hyperdivergent pattern of the patient. The control of the lower occlusal plane, as well as its rotation in a counterclockwise direction, was made necessary to promote closure of the anterior open bite. This aspect was obtained with the use of specific mechanics, with origin in points of skeletal anchorage on the upper arch (mini-implants) (Fig 22). The mechanic described followed the directional force principles of Tweed-Merrifield technique. ${ }^{12}$

The treatment itself had its start with the extraction of the lower third molars, the installation of mini-implants between teeth \#15-\#16 and \#25-\#26, and the setting of $0.022 \times 0.028$-in Edgewise standard metal brackets in both arches, except on the lower incisors that were included only in a posterior step of the treatment.

The superior arch had its normal sequence of alignment and leveling with 0.014-in NiTi wire, as well as 0.016 -in; 0.018-in and 0.020-in, and finally with a $0.018 \times 0.025-i n$, stainless steel archwire. In the lower arch a specific mechanic was applied to perform vertical control and distalization of the lower 
teeth after the removal of the third molars. The miniimplants on the posterior region of the upper arch worked as points of skeletal anchorage, in order to apply intermaxillary mechanics with Class III direction. The presence of those devices resulted on several advantages, such as: 1) It completely eliminated the undesirable effects of intermaxillary mechanics on the upper arch, which would provide an even bigger projection of upper incisors. 2) The direction of the high-pull on the anterior region of the lower arch gave a vigorous vertical control, promoting counterclockwise rotation of the lower occlusal plane, so important for the evolution of the treatment during distalization of the lower teeth and closure of the open bite, quite similar to the high pull J-hook extraoral device on the lower arch, as described and applied on the technique by Tweed-Merrifield ${ }^{12}$ (Figs 22 to 25).

As the posterior region of the lower arch presented a relative degree of alignment and leveling, the treatment started with a $0.017 \times 0.022$-in rectangular stainless steel archwire, passively adapted, highlighting only the presence of tip back bends with intensity of about $30^{\circ}$ on teeth \#37 and \#47.

Molar correction was performed with the help of long sliding jigs that received elastics from mini-implants on the upper arch (Fig 23). Those jigs were near the tubes on teeth \#37 and \#47, extending anteriorly until the canine distal surface. The force exerted by the elastics $(150 \mathrm{~g})$ on the high pull potentiated the distal inclination bends of teeth \#37 and \#47, distalizing them, at the same time in which promoted efficient control of the lower occlusal plane (Figs 22 and 23). As the second molars were distalized and reached their proper place, the jigs were being transferred to the next molar, and so on.

When posteroinferior teeth had already been considerably distalized, so that some diastemas appeared between the canines and the lateral incisors, the incisors were included in the treatment. A 0.018-in archwire with " $\mathrm{T}$ " loops, to allow for the correct alignment and leveling of these teeth, replaced the rectangular arch. However, the intermaxillary mechanics continued.

After alignment and leveling of incisors, a new $0.018 \times 0.025$-in rectangular lower archwire was made. Intermaxillary mechanics persisted until the achievement of the molar and canine Class I occlusion, and the establishment of adequate overbite and overjet.

Then, upper and lower $0.019 \times 0.026$-in stainless steel archwires, in an ideal form were made, individualized as needed for adequate finishing. The retention on the upper arch was done with a wraparound type plate, and on the lower arch with intercanine fixed retainer made with 0,032-in wire.
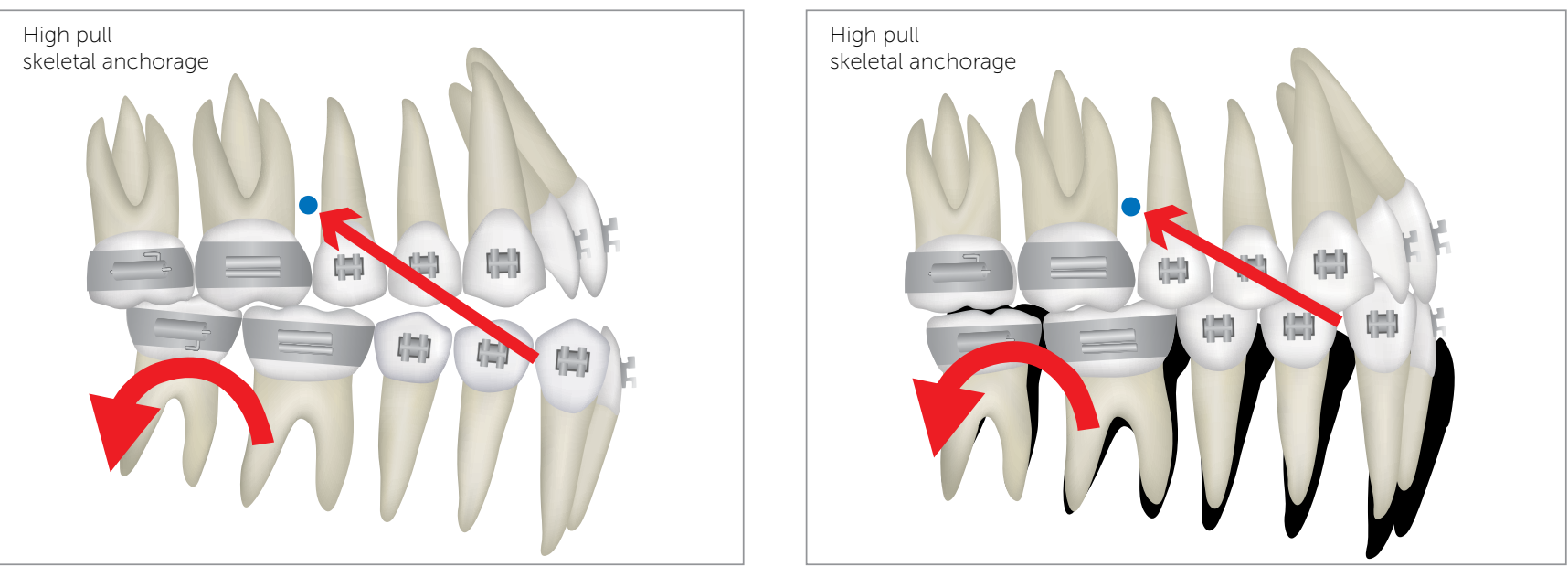

Figure 22 - Illustration of the Class III mechanics employed in the vertical control, anchored in mini-implants on the upper arch, between the first molars and second premolars 

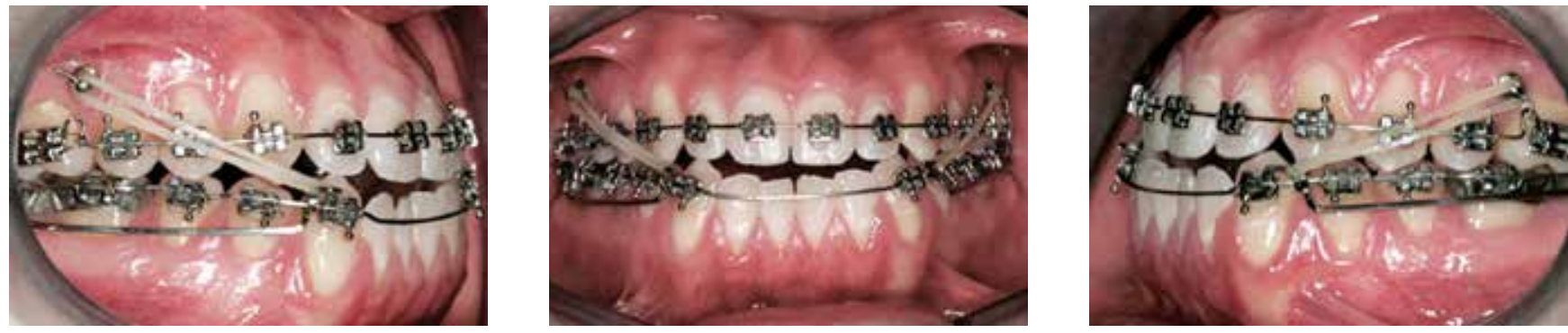

Figure $\mathbf{2 3}$ - Initial step of treatment. Class III mechanics supported by mini-implants (upper arch) and with sliding jigs (lower arch).
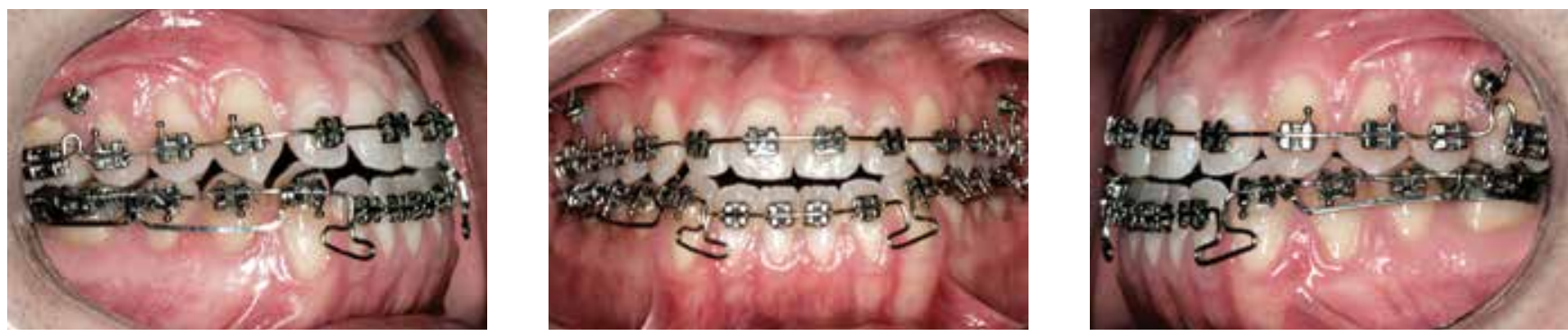

Figure 24 - Intermediate treatment step. Lower incisors were included after reasonable distalization of the other teeth in this arch. Observe the control of the lower occlusal plane, as well as the closure of the bite, produced by Class III mechanics supported by mini-implants.
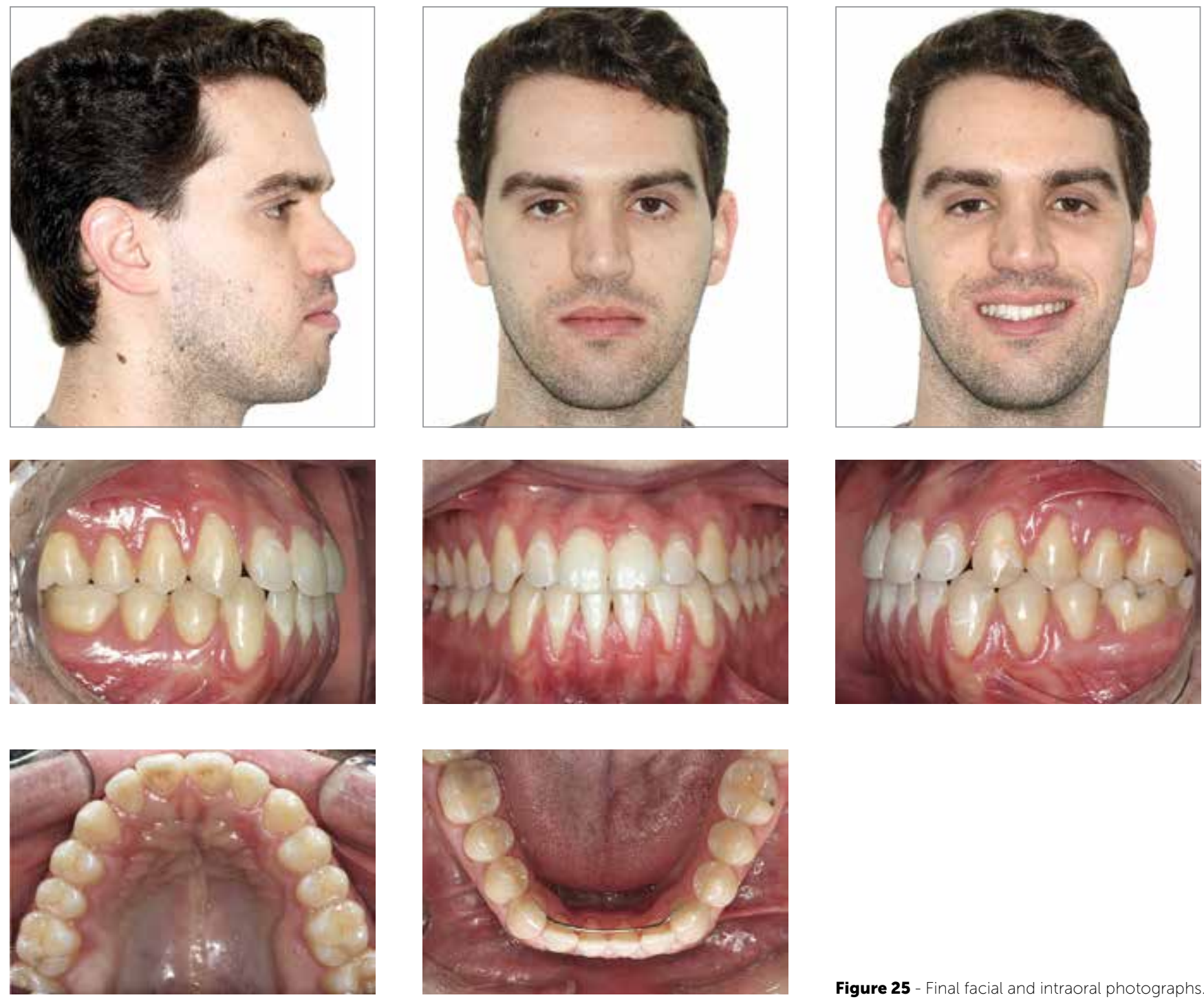

Figure 25 - Final facial and intraoral photographs. 


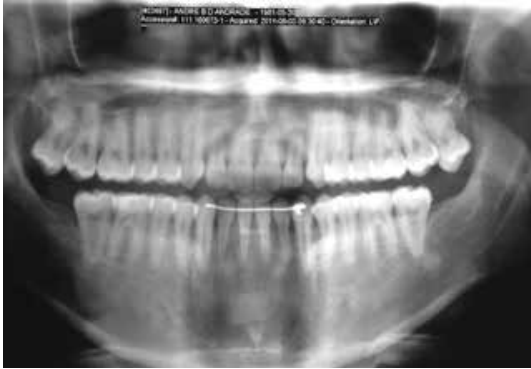

Figure $\mathbf{2 6}$ - Final panoramic radiograph.

Figure 28 - Total $(\mathbf{A})$ and partial (B) superimpositions of initial (black) and final (red) cephalometric tracings.
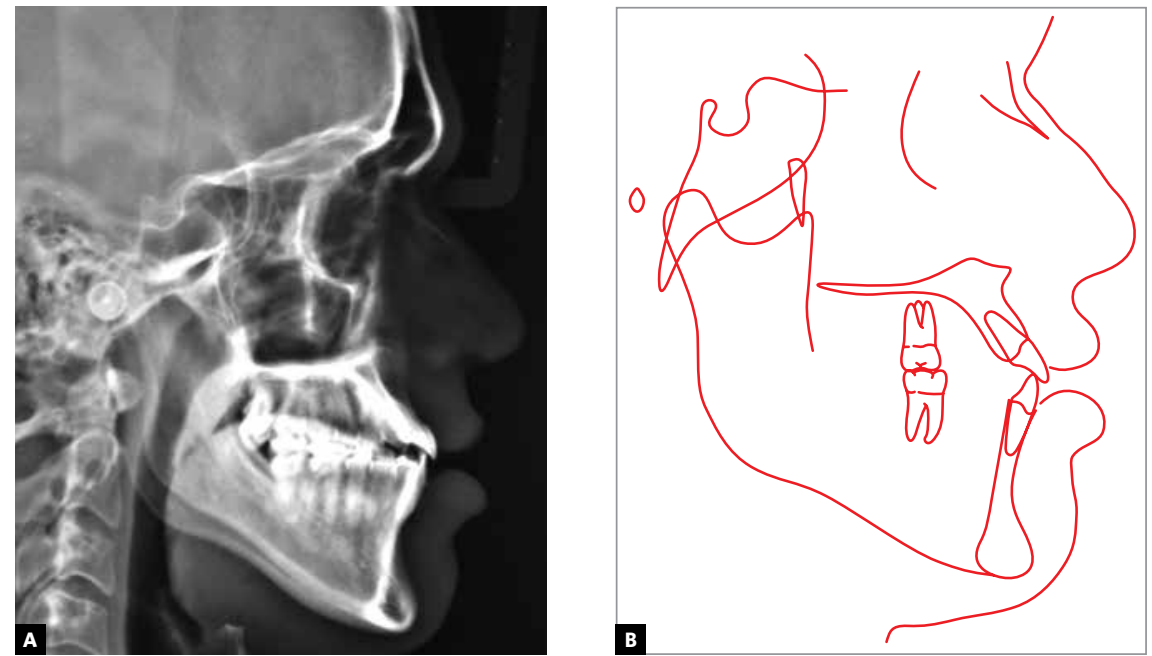

Figure 27 - Final lateral cephalometric radiograph $(\mathbf{A})$, and cephalometric tracing (B)
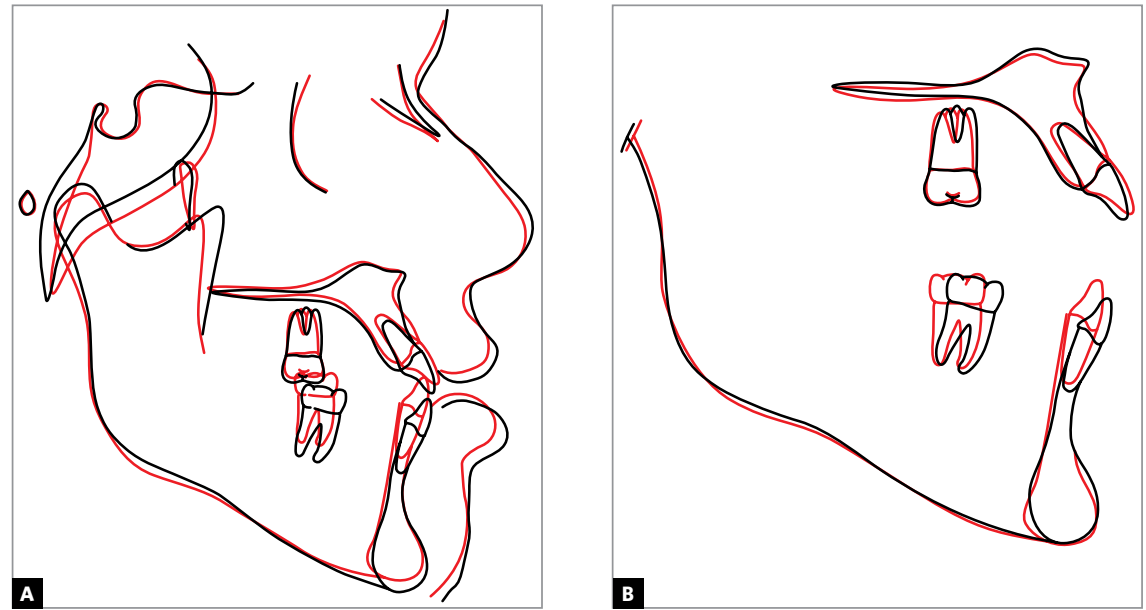

Table 3 - Summary of cephalometric measurements.

\begin{tabular}{|c|c|c|c|c|c|c|}
\hline & \multicolumn{2}{|c|}{ Measures } & Normal & A & B & A/B diff. \\
\hline \multirow{8}{*}{ Skeletal pattern } & SNA & (Steiner) & $82^{\circ}$ & $79^{\circ}$ & $78^{\circ}$ & 1 \\
\hline & SNB & (Steiner) & $80^{\circ}$ & $80^{\circ}$ & $79^{\circ}$ & 1 \\
\hline & ANB & (Steiner) & $2^{\circ}$ & $-1^{\circ}$ & $-1^{\circ}$ & 0 \\
\hline & Convexity angle & (Downs) & $0^{\circ}$ & $-6^{\circ}$ & $-7^{\circ}$ & 1 \\
\hline & $Y$ axis & (Downs) & $59^{\circ}$ & $57^{\circ}$ & $57^{\circ}$ & 0 \\
\hline & Facial angle & (Downs) & $87^{\circ}$ & $94^{\circ}$ & $93^{\circ}$ & 1 \\
\hline & SN-GoGn & (Steiner) & $32^{\circ}$ & $34^{\circ}$ & $32^{\circ}$ & 2 \\
\hline & FMA & (Tweed) & $25^{\circ}$ & $27^{\circ}$ & $24^{\circ}$ & 3 \\
\hline \multirow{6}{*}{ Dental pattern } & IMPA & (Tweed) & $90^{\circ}$ & $85^{\circ}$ & $83^{\circ}$ & 2 \\
\hline & 1.NA (degrees) & (Steiner) & $22^{\circ}$ & $33^{\circ}$ & $42^{\circ}$ & 9 \\
\hline & 1-NA (mm) & (Steiner) & $4 \mathrm{~mm}$ & $8 \mathrm{~mm}$ & $11 \mathrm{~mm}$ & 3 \\
\hline & I.NB (degrees) & (Steiner) & $25^{\circ}$ & $23^{\circ}$ & $18^{\circ}$ & 5 \\
\hline & $1-N B(m m)$ & (Steiner) & $4 \mathrm{~mm}$ & $7 \mathrm{~mm}$ & $6 \mathrm{~mm}$ & 1 \\
\hline & $\frac{1}{1}$-Interincisal Angle & (Downs) & $130^{\circ}$ & $124^{\circ}$ & $122^{\circ}$ & 2 \\
\hline \multirow{2}{*}{ Profile } & Upper Lip - S Line & (Steiner) & $0 \mathrm{~mm}$ & $0.5 \mathrm{~mm}$ & $0 \mathrm{~mm}$ & 0.5 \\
\hline & Lower Lip - S Line & (Steiner) & $0 \mathrm{~mm}$ & $6 \mathrm{~mm}$ & $4 \mathrm{~mm}$ & 2 \\
\hline
\end{tabular}




\section{Analysis of results}

The main objectives of the treatment were accomplished, establishing an adequate dental relationship, with significative improvement on esthetics of the smile, with the minimization of lower incisor exposure (Fig 25). No important repercussion was noticed on general facial esthetics, since that was not an original objective. It is worthy to highlight that a preponderant factor for the success of the treatment was patient collaboration on the use of intermaxillary elastics. Skeletal alterations can be summarized on mandibular counterclockwise rotation, with decrease of $2^{\circ}$, at $\mathrm{SN}-\mathrm{GoGn}$ (from $34^{\circ}$ to $32^{\circ}$ ), proving the efficient control of used mechanics (Figs 27 and 28, and Table 3). From the dental point of view, there was and increase of upper incisor inclination, with 1-NA from $33^{\circ}$ to $42^{\circ}$, and slight retroinclination and extrusion of lower incisors, $1-\mathrm{NB}$ from $23^{\circ}$ to $18^{\circ}$, effecting directly on the closure of the open bite (Fig 27 and 28, and Table 3).

A Class I relationship on canines and molars was obtained, and the anterior open bite was corrected. Alignment, leveling, and inclination and rotation correction were successfully achieved (Fig 17). There was a slight increase of gingival recessions on the region of lower incisors, but not in a single moment that fact could be attributed to dental movement, since those movements were slowly accomplished, with lingual inclination. The patient admitted to persist with inadequate brushing, which surely contributed to this situation. He was referred to evaluation by a periodontist, regarding the need for performing free gingival grafts.

REFERENCES

1. Proffit WR. Ortodontia contemporânea. 3ạ ed. Rio de Janeiro: Guanabara Koogan; 2002.

2. Jiuxiang $L$, Yan $G$. Preliminary investigation of nonsurgical treatment of severe skeletal Class III malocclusion in the permanent dentition. Angle Orthod. 2003:73(4):401-10.

3. Silva AAF, Manganello-Souza LC, Freitas SLA. Tratamento das deformidades maxilofaciais. Rev Bras Cir Craniomaxilofac. 2009;2(3):129-32.

4. Troy BA, Shanker S, Fields HW, Vig K, Johnston W. Comparison of incisor inclination in patients with Class III malocclusion treated with orthognathic surgery or orthodontic camouflage. Am J Orthod Dentofacial Orthop. 2009:135(2):146.e1-9; discussion 146-7.

5. Burns NR, Musich DR, Martin C, Razmus T, Gunel E, Ngan P. Class III camouflage treatment: what are the limits? Am J Orthod Dentofacial Orthop. 2010 Jan;137(1):9.e1-9.e13; discussion 9-11.

6. Sakai A, Haraguchi S, Takada K. Orthodontic camouflage of a late adolescent patient with Class III malocclusion. Orthod Waves. 2006:65(3):127-33.

\section{CONCLUSION}

On the importance of vertical control on Class III orthodontic compensatory treatment (camouflage), we understand that:

1. The control of the occlusal plane and of the mandibular plane provided by efficient and easily applied mechanics can bring benefits that characterize Class III compensatory treatment as a great alternative for the resolution of those problems. It is important to highlight that there are limitations, and that not every case can be treated in a compensatory manner.

2. Orthodontic camouflage is not able to produce great changes on the face, neither to correct asymmetry, that is, it should not be used on patients who yearn for great facial esthetics alteration, who, therefore, are candidates to orthognathic surgery.

3. It is important to highlight that, in cases treated with orthodontic camouflage, skeletal discrepancy remains. Therefore, it is most important to verify in detail the patient's complaint before beginning any kind of treatment. That prevents future frustration regarding the result achieved at the end of the treatment. ${ }^{3}$

4. Orthodontics is not a exact science, therefore, it is the clinical experience of the professional that will dictate treatment planning, always paying attention to the limitations and particularities of each patient, in order to raise the possibilities of treatment success.

Ning F, Duan Y, Huo N. Camouflage treatment in skeletal Class III cases combined with severe crowding by extraction of four premolars. Orthod Waves. 2009;68(2):80-7.

8. Mihalik CA, Proffit WR, Phillips C. Long-term follow-up of Class II adults treated with orthodontic camouflage: A comparison with orthognathic surgery outcomes. Am J Orthod Dentofacial Orthop. 2003;123(3):266-78.

9. Bishara SE. Class II malocclusions: diagnostic and clinical considerations with and without treatment. Semin Orthod. 2006;12(1):11-24.

10. Araújo TM. Cefalometria, conceitos e análises [tese]. Rio de Janeiro (RJ): Universidade Federal do Rio de Janeiro; 1983

11. Arnett W, Bergman RT. Facial keys to orthodontic diagnosis and treatment planning-part II. Am J Orthod Dentofacial Orthop. 1993:103(5):395-411.

12. Merrifield L. Edgewise sequential directional force technology. J Charles $\mathrm{H}$. Tweed Int Found. 1986;14:22-37 